
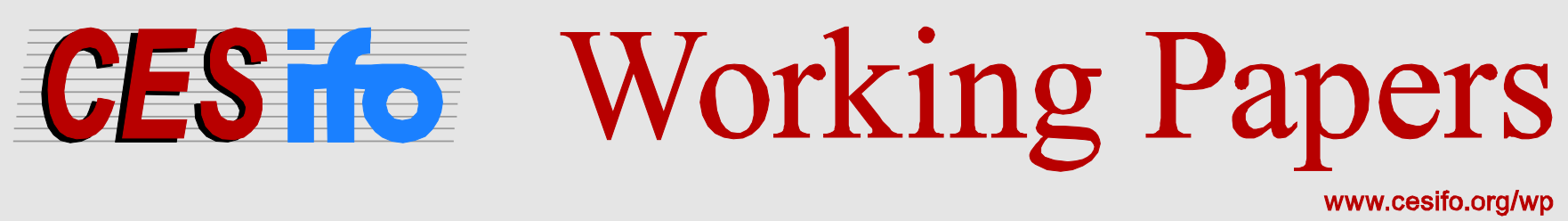

\title{
Consuming your Way to Efficiency: Public Goods Provision through Non-Distortionary Tax Lotteries
}

\author{
Thomas Giebe \\ Paul Schweinzer
}

CESIFO WORKING PAPER NO. 4228

CATEgory 1: Public FinANCE

MAY 2013

An electronic version of the paper may be downloaded

- from the SSRN website:

- from the RePEc website:

- from the CESifo website:

WwW.SSRN.com

www.RePEc.org

www.CESifo-group.org/wp

\section{CESifo}




\title{
Consuming your Way to Efficiency: Public Goods Provision through Non-Distortionary Tax Lotteries
}

\begin{abstract}
We revisit the classical result that financing a pure public good through taxation of private consumption is inefficient. To this standard setup we add a consumption contest in which consumers can win a prize. We show that an appropriately chosen contest-which we call a 'tax lottery' - can correct the distortion in private consumption while, at the same time, inducing efficient provision of the public good and balancing the government's budget. The result does not depend on whether the public good is provided exogenously or dependent on actual tax revenue. We show that neither pure fundraising contests nor a sales tax combined with a 'simple' lottery can induce efficiency in the standard environment.
\end{abstract}

JEL-Code: C700, D700, H000.

Keywords: public goods, taxation, contests, lotteries.

Thomas Giebe

Microeconomics

Technical University Berlin

Straße des 17. Juni 135

Germany - 10623 Berlin

thomas.giebe@tu-berlin.de
Paul Schweinzer

Department of Economics

University of York

Heslington, York YO10 5DD

United Kingdom

paul.schweinzer@york.ac.uk

Thanks to Felix Bierbrauer, Qiang Fu, Alex Gershkov, Martin Kolmar, Alan Krause, Jianpei Li, Yushan Lo, John Morgan, Arnold Polanski, Rudi Stracke, and Cédric Wasser for helpful comments and discussions. Financial support from the German Science Foundation through SFB/TR 15 and from the University of York Research and Impact Support Fund is gratefully acknowledged. Giebe thanks for the hospitality of the University of York and Schweinzer appreciates the generous hospitality of CESifo, Munich. (24-Apr-2013) 


\section{Introduction}

The mechanism we study shares important properties with existing mechanisms like the Taiwanese Uniform Invoice lottery. ${ }^{1}$ Under this system, every one of the roughly 11.5 billion receipts issued annually by Taiwanese shops comes with a unique lottery number, which enters a bi-monthly prize draw awarding prizes of up to $\$ 320,000$. This receipt lottery was introduced in 1951 to increase tax revenue and proved so successful that it remained in place ever since. Since the lottery numbers come per receipt rather than per dollar spent, there is an incentive for customers to pay for every single item separately in order to get more receipts: a scene which many Taiwanese are familiar with. A similar example are the recently introduced Chinese tax receipt lotteries. Under this scheme, each receipt for restaurant consumption or entertainment expenditures is a lottery scratch card creating incentives for customers to ask for receipts and, in turn, oblige restaurants to pay VAT. ${ }^{2}$ Examples of designed lotteries, that is, of lotteries where the winning probabilities are not just the number of tickets bought over the total number of tickets, are the German or Austrian Klassenlotterien and the United Kingdom Premium Bonds. ${ }^{3}$ Both schemes directly finance public goods. While all these examples provide motivation for some aspects of our setup, we do not try to model the entirety of any of these schemes and we also do not try to explain empirical observations relating to their application.

We show that the benefits of combining a sales tax with lottery incentives go beyond the successful reduction of tax evasion. The contribution of this paper is to provide the novel benchmark result that such a mechanism can correct the distortions caused by taxing private consumption, solving the classical public goods provision problem.

The standard, complete information textbook environment in which we present this result is composed of some private good and a public good. In this environment, a sales tax on the consumption of the private good does not allow the efficient provision of the public good. To this setup, we add a specifically designed lottery-or, synonymously, a contest-which translates private good consumption expenditures into winning probabilities (or lottery tickets) for some part of overall tax proceeds. This gives incentives to consume more of the private good, thus increasing tax revenue and counterbalancing the distortion from taxation. We show that, if one part of the raised tax is used to finance the public good and the other part is employed as incentive prize for the lottery, then it is possible to obtain full efficiency in both private and public goods consumption. ${ }^{4}$

\footnotetext{
${ }^{1}$ http://en.wikipedia.org/wiki/Uniform_Invoice_lottery. Puerto Rico introduced a similar system in 2011; its official site is http://loteriaelectronicapr.com/. The municipality of São Paulo returns through its Nota Fiscal Paulista tax lottery program $30 \%$ of proceeds in the form of cash prizes mainly in order to combat tax evasion; see http://www.nfp.fazenda.sp.gov.br/.

2 For details see, for instance, Wan (2010).

3 For details see, for instance, Schönbein (2008) or http://www.nsandi.com/products/pb.

4 To focus ideas, we propose the following stylised application in the local government provision of a public good. There is a small number of players on whom the designer may conceivably be well informed. Tying, for instance, the payment of social hardship benefits to the 'consumption' of labour through a specific tax would then be entirely natural but, as discussed below, result in a necessarily inefficient allocation. What we show is that one can restore efficiency by designing a lottery which rewards local employers relative to their 'consumption' of labour, with some prize taken from the specific tax proceeds. Alternatively, as is usually the case with contests, the prize can be interpreted as a tax rebate that is handed out ex-post in specifically designed proportions.
} 
A weaker, second-best version of this result continues to hold under private information.

Throughout the paper, we analyse two ways of providing the public good. In the first, 'exogenous' setting, the government can provide the public good exogenously at the efficient level. Then the players' consumption decisions affect only the amount of money raised. This first setting raises the question whether the mechanism can balance the government's budget in equilibrium, while inducing efficient private consumption. In the second, 'endogenous' setup, the government provides the public good directly from the share of tax revenue that is not paid out as a prize in the contest. This setting balances the government's budget by definition and the players take into account that their consumption decisions affect the provision level of the public good, introducing a free-rider problem. The second scenario raises the question whether the mechanism can induce efficiency in both the public and the private good dimensions.

The tax lottery scheme is individually rational and unanimously accepted if proposed. It implements efficient allocations in pure-strategy Nash equilibrium, through direct taxes in an environment where the consumption utility of private and public goods is non-separable. In contrast to alternative mechanisms, we do not require threats of punishments or a commitment not to produce the public good in case of insufficient funding. The tax lottery scheme provides a degree of freedom for the designer which, for instance, allows an efficient contest to be designed for an exogenously given sales tax rate.

In this paper, we analyse a classical environment in which, e.g., lump-sum taxation can directly implement efficiency. Thus, efficiency per se is not our issue. We are motivated by theoretical interest in the tax receipt lottery examples mentioned above. Our contribution is to point out that a sales tax in combination with an appropriately designed contest can induce efficiency, while neither of the two can achieve efficiency on their own.

\section{Literature}

At least since Samuelson (1954), it is well-known that a sales tax cannot finance a pure public good efficiently since it distorts private consumption. The main idea behind our tax lottery scheme is that a contest that is tied to private consumption induces additional consumption. This has two benefits: it counterbalances the distortion due to the sales tax and it raises additional revenue. If the contest is designed appropriately, then the tax revenue is sufficient to finance both the contest and the public good - at the efficient level-while fully correcting the distortion in private consumption. Not all contests, however, can be used to implement efficiency. 'Simple' lotteries, i.e., lotteries where the probability of winning just equals the share a player owns of all tickets, fail to induce efficiency. Moreover, we show that running a pure fundraising contest without a sales tax is inefficient, too.

The paper interprets the consumption contest as a single-prize lottery where winning probabilities are determined from individual shares of total private consumption. We would like to point out prominently, however, that this is entirely equivalent to interpreting a player's probability of winning as the share of the tax revenue that is allocated to a player in dependence of all players' consumption expenditures. Since this interpretation does not require the transfer of large payments to a 'winning' player, it might well be a more practically fruitful way to read our model as returning consumption- 
dependent tax rebates to consumers. Formally, the two interpretations are identical and, therefore, the paper develops only the classic contest interpretation using winning probabilities.

To use lotteries for fundraising purposes is not a new idea. ${ }^{5}$ Nevertheless, we are only aware of a handful of papers developing ideas directly related to this paper, that is, to public goods provision through contests. We would like to briefly discuss these mostly recent papers in the following short review. ${ }^{6}$ As a general rule and contrary to our analysis, these papers are mainly concerned with the fundraising capabilities of given mechanisms and not with designing efficiency inducing mechanisms. From a technical modelling point of view, they usually employ separable (quasi-linear) utility while we include a (taxed) private good in the analysis and allow for the utility of private and public good to be nonseparable. The standard setup deals at heart with the case of perfect information.

Morgan (2000) is the first to study various fundraising mechanisms for the purpose of the supply of a public good. He is mainly interested in 'raffles,' i.e., the 'simple' lottery case of our environment, without considering a private good or its taxation. ${ }^{7}$ He shows that these mechanisms are generally inefficient but can outperform voluntary contributions. If the lottery prize is fixed in advance, then the degree of efficiency obtained is a function of the prize size. Thus, with a sufficiently large prize (and correspondingly large individual monetary endowments) the mechanism comes arbitrarily close to, but never reaches, efficiency. If the prize is a percentage of contributions, then the lottery does not perform better than voluntary contributions. Although our setting differs substantially-we are interested in the taxation of a private good which does not appear in Morgan's setup-we can nevertheless confirm several of his results in our environment. We are, however, able to reverse his main inefficiency finding by considering a richer class of contests including those governed by 'generalised' Tullock success functions. Franke and Leininger (2013) extend Morgan (2000) in discussing a biased, 'unfair,' indirect contribution game which provides the efficient amount of the public good in asymmetric Nash equilibrium. As Morgan, they focus attention on voluntary contribution or 'raffles' schemes while we explore the potential for efficiency in a taxation model. Interestingly, their optimally biased game can be understood as a non-cooperative implementation of Lindahl prices.

Goeree, Maasland, Onderstal, and Turner (2005) do not analyse lotteries but introduce a general class of incomplete-information all-pay auctions, rank their revenues, and illustrate the extent to which they dominate winner-pay auctions and lotteries. Moreover, they identify the optimal fundraising mechanism as being of the all-pay format they investigate. This optimal mechanism is

\footnotetext{
5 'A Lottery is a Taxation, Upon all the Fools in Creation; And Heavn be praisd, It is easily raisd, Credulitys always in Fashion; For, Follys a Fund, Will never lose Ground; While Fools are so rife in the Nation." Henry Fielding, The Lottery (London: J. Watts, 1732), Scene 1, quoted in Clotfelter and Cook $(1989,219)$. Earlier still, according to Karoshi (2008), Keno lottery slips from the Chinese Han Dynasty (205-187 B.C.) are believed to have helped financing the construction of the Great Wall of China.

${ }^{6}$ The idea that in some circumstances efficiency can be induced through a rank order tournament is due to Lazear and Rosen (1981). In these tournaments, prizes are allocated according to a relative ranking, hence ordinal information on performance is sufficient. This idea has found numerous applications and extensions, for instance in the work of Green and Stokey (1983), Nalebuff and Stiglitz (1983), Dixit (1987), Moldovanu and Sela (2001), or Siegel (2009). For a detailed survey of the contests literature see the comprehensive Konrad (2008).

${ }^{7}$ Morgan (2000) also surveys several alternative mechanisms and points out their weaknesses, e.g., mixed experimental evidence of the theoretical predictions or the requirement of coercive power, and stresses the informational requirements on the designer's side.
} 
generally inefficient. Bos (2011) shows that the result of their indirect mechanism design approach does not carry over to complete information. He gives examples of asymmetries for which the lottery outperforms their optimal charity auctions. In a similar vein, Duffy and Matros (2012) show that, with fixed and self-financed prizes, lotteries can outperform all-pay auctions in terms of expected public good provision levels. Their experimental investigation of this phenomenon, however, shows no significant difference in public goods contribution levels across the two mechanisms.

While in our paper the public good is produced by a third party, e.g., the government, Kolmar and Wagener (2011) analyse the problem of private production of a public good with the help of contests in an environment with asymmetric individuals and heterogeneous provision productivities. In their main 'sorting' result, the contest motivates highly productive individuals to contribute to the public good while low-productivity individuals divert their efforts to the private good. Similarly, Kolmar and Sisak (2011) analyse the private provision of a public good by players who are heterogeneous with respect to utility and cost of producing the public good. The paper discusses the use of multiple prize contests in order to implement efficiency. In both papers, the contest prizes are exogenously financed from lump-sum taxation. In contrast, funds are raised through a distortive sales tax in our paper. In our (classical) framework, lump sum taxation would directly implement efficiency, making a contest obsolete.

In the way our tax lotteries are designed to achieve efficient allocations in the presence of freerider problems, the present paper relates to two other recent contest-based studies: Gershkov, Li, and Schweinzer (2009) show that a contest can overcome the moral-hazard-in-teams problem, and Roussillon and Schweinzer (2010) design a contest to address the incentives to free-ride on emissions reduction in international agreements. Both papers tailor mechanisms to their specific environments which cannot be used to address the general public goods provision problem the present analysis deals with.

Recently, and following Morgan and Sefton (2000), there has been considerable experimental interest in the public goods provision problem involving contests. ${ }^{8}$ The empirical relevance of the use of lottery money for financing public goods is testified to by, for instance, Landry and Price (2007). For a critical appraisal of tax lotteries see Hansen (2005) or Moir and Childs (2005).

A recent contribution to the classical literature on complete information public goods provision is Buchholz, Cornes, and Rübbelke (2011). The authors study equilibrium existence in an aggregative game on which they impose the efficient allocation. In particular, they analyse the income distributions for which a matching mechanism (in which agents cross-subsidise each other) can be compatible with voluntary and efficient provision of the public good. In contrast to the present analysis, the authors do not explore the design of explicit mechanisms capable of providing incentives for the implementation of this efficient matching equilibrium.

It is impossible to review the vast and active literature on (optimal) taxation here; a recent example exploring comparative statics in a kindred framework is Brett and Weymark (2008). Recent and comprehensive surveys of this literature, including discussions of the classical remedies to public

\footnotetext{
${ }^{8}$ Recent contributions to the experimental study of contests relating to public goods include Orzen (2005), Lange, List, and Price (2007), Carpenter, Holmes, and Matthews (2008), Schram and Onderstal (2009), Corazzini, Faravelli, and Stanca (2010), and Duffy and Matros (2012).
} 
goods provision problems in the form of lump-sum and Pigouvian taxation, Lindahl equilibria and Coasian bargaining, are provided by Silvestre (2003) and Mankiw, Weinzierl, and Yagan (2009), among others. We can similarly only mention the large literature on variants of Vickrey-ClarkeGroves mechanisms applied to taxation problems which transcends our framework by allowing for incomplete information on preferences. An example applicable directly to public goods provision is Ledyard and Palfrey (1994), modern contributions include, for instance, Bierbrauer (2009) or Bierbrauer and Hellwig (2009). ${ }^{9}$

The paper is structured as follows: In the next section, after the definition of the environment, we give a short taxonomy of well-known approaches to the problem of public goods provision that are directly relevant for our scheme. We then present the model of tax lotteries in section 3 and illustrate the idea through example. Although highly stylised, this simple example conveys much of the intuition of the general perfect information results presented in section 4 . We conclude with a discussion of the merits of our approach following the evaluation of a set of model extensions which includes a discussion of private information. Proofs and details can be found in the appendix.

\section{The environment and a taxonomy of approaches}

There is a set $\mathcal{N}$ of $n>1$ identical individuals $i \in \mathcal{N}$ who each consume a pure public good, $G$, and can purchase quantities $x_{i} \in[0, \infty), \mathbf{x}=\left(x_{1}, \ldots, x_{n}\right)$, of a private good. There is a numeraire good (money), $c_{i}$. Individual utility $u_{i}(\cdot)$ is assumed to be additively separable in consumption utility, $v\left(x_{i}, G\right)$, and money. We do not require consumption utility to be separable in the public and private good. The individual's budget constraint is $w=p x_{i}+c_{i}$, where $w$ is the monetary endowment and $p$ is the unit price of the private good. We assume the latter to be unperturbed by taxation. Thus, individual $i$ maximises

$$
\begin{aligned}
u_{i}\left(c_{i}, x_{i}, G\right) & =c_{i}+v\left(x_{i}, G\right), \quad \text { s.t. } w=p x_{i}+c_{i} \\
\Rightarrow \quad u_{i}\left(x_{i}, G\right) & =w+v\left(x_{i}, G\right)-p x_{i} .
\end{aligned}
$$

The public good is produced by the government at strictly monotonic and differentiable cost $C(G)$ and we assume $v$ to be strictly quasi-concave in both arguments. In this environment, efficiency is defined by the quantities $\mathrm{x}^{*}$ and $G^{*}$ solving ${ }^{10}$

$$
\left(\mathbf{x}^{*}, G^{*}\right) \in \underset{\left(x_{1}, \ldots, x_{n}, G\right)}{\operatorname{argmax}} \sum_{i=1}^{n} u_{i}\left(x_{i}, G\right)-C(G) .
$$

We denote the derivatives of $v$ with respect to its two arguments by $v_{x}=\frac{\partial v\left(x_{i}, G\right)}{\partial x_{i}}$ and $v_{G}=\frac{\partial v\left(x_{i}, G\right)}{\partial G}$. Imposing symmetry, $x_{1}=\cdots=x_{n}$, the efficient quantities are characterised by the first-order

\footnotetext{
${ }^{9}$ Although we make no attempt to systematically explore an incomplete information incarnation of our mechanism in this paper, we nevertheless develop a simple private information extension to our results in subsection 5.2. There, the government cannot distinguish between consumers and must therefore set a single, anonymous tax lottery rate for heterogenous consumers. It turn out that in this, perhaps more realistic private information setup, the optimal tax lottery always outperforms a simple optimal tax in terms of welfare.

10 Throughout the paper, we assume that there is an interior efficient solution.
} 
conditions

$$
\begin{aligned}
n v_{G}\left(x_{i}^{*}, G^{*}\right) & =C^{\prime}\left(G^{*}\right), \\
v_{x}\left(x_{i}^{*}, G^{*}\right) & =p, \quad i=1, \ldots, n,
\end{aligned}
$$

where (3) is the well-known Samuelson condition. ${ }^{11}$ If the government commits to providing the public good exogenously at the efficient level $G^{*}$, then, absent any taxes, individual $i$ maximises $u_{i}\left(x_{i}, G^{*}\right)$, choosing the efficient quantity $x_{i}^{*}$ that solves the first-order condition

$$
\frac{\partial u_{i}\left(x_{i}, G^{*}\right)}{\partial x_{i}}=0 \quad \Longleftrightarrow \quad v_{x}\left(x_{i}, G^{*}\right)=p
$$

It is well-known that, in this setting, a lump sum tax on the numeraire good, equal to $C\left(G^{*}\right) / n$, is efficient since it does not distort the above private consumption decision, while balancing the government's budget. Moreover, a uniform commodity tax, $t$ on the private good and the numeraire good is efficient, too. ${ }^{12}$

In accordance with our examples in the introduction, we therefore consider a situation where the public good is (at least partially) financed by a sales tax on the consumption good. Although the sales tax is distortionary, we want to show that an appropriately designed lottery, in addition to a given sales tax, can implement efficiency. As we will show, neither a sales tax nor a lottery similar to the one we study as part of our tax lotteries are capable of achieving efficiency on their own.

In the remainder of this section we look at alternative mechanisms financing the public good from various sources. ${ }^{13}$ In each case, we distinguish two ways of how the government provides the public good. First, the government might commit to providing the public good at the efficient level $G^{*}$, independent of actual tax revenue. Therefore, players cannot affect the public good's provision level. The question in this scenario is whether it is possible to balance the government's budget in equilibrium, i.e., to exactly cover the cost of the efficient provision of the public good, $C\left(G^{*}\right)$. Second, the government might simply provide the level of public good that corresponds to the amount of money raised from the players. Thus, the government budget is always balanced, in and outside of equilibrium. In this setting, players take into account their decision's effect on the public good, and the question is whether the efficient level of the public good can be achieved. In both cases we want to achieve an equilibrium that implements efficiency in the private as well as in the public goods dimensions while at the same time balancing the government's budget. We start our short taxonomy with two classical mechanisms which are known to be inefficient in this setting.

\footnotetext{
11 Samuelson (1954) shows that individually rational decisions fail to achieve efficiency.

12 In the latter case, the individual's budget constraint changes to $w=(1+t) p x_{i}+(1+t) c_{i}$. The utility maximisation problem becomes $\max _{x_{i}} \frac{w}{1+t}+v\left(x_{i}, G\right)-p x_{i}$, which leads to an efficient individual decision for the given amount of the public good, $G, v_{x}\left(x_{i}, G\right)=p$.

13 Throughout the discussion of competing approaches we assume that an interior solution to the social planner's problem exists. In most of section 2 we do not discuss the second-order conditions because the first-order condition is already inconsistent with efficiency.
} 
2.1 A sales tax alone is inefficient. Suppose that there is a sales tax $\alpha$ on the private good. First, the public good is provided efficiently at $G=G^{*}$, independent of actual tax revenue. The budget constraint is $w=(1+\alpha) p x_{i}+c_{i}$ and an individual maximises

$$
\max _{x_{i}} w+v\left(x_{i}, G^{*}\right)-(1+\alpha) p x_{i}
$$

The first-order condition of this problem is

$$
v_{x}\left(x_{i}, G^{*}\right)=(1+\alpha) p
$$

which implies that consumption of the private good is distorted as long as $\alpha>0$, see (5). ${ }^{14}$

Second, suppose that the public good is financed entirely from tax revenue, i.e., the government budget constraint is

$$
C(G)=\sum_{i=1}^{n} \alpha p x_{i} \quad \Longleftrightarrow \quad G=C^{-1}(C(G))=C^{-1}\left(\alpha p \sum_{i=1}^{n} x_{i}\right)
$$

The payoff changes since individual $i$ now takes into account the effect of own consumption on the amount of the public good:

$$
\max _{x_{i}} w+v\left(x_{i}, G\right)-(1+\alpha) p x_{i}, \quad \text { s.t. } C(G)=\alpha p \sum_{i=1}^{n} x_{i}
$$

with first-order condition

$$
v_{x}\left(x_{i}, G\right)+\left(v_{G}\left(x_{i}, G\right) \frac{1}{C^{\prime}(G)}-1\right) \alpha p=p .
$$

By changing the tax rate $\alpha$, the government thus affects the level of individual consumption, and, at the same time, the provision level of the public good. Efficiency in the private good dimension requires that the parenthesis in (10) vanish, i.e., $v_{G}=C^{\prime}(G)$, equalising (10) with (4). However, the condition for efficiency in the public good dimension is (3), the Samuelson condition. Obviously, the conditions $v_{G}=C^{\prime}(G)$ and $n v_{G}=C^{\prime}(G)$ are inconsistent for $n>1$. This illustrates a well-known free rider problem: the Samuelson condition cannot be satisfied under individual utility maximisation. Thus, the sales tax $\alpha$ cannot induce efficiency in both dimensions.

The above demonstrates that a sales tax alone is incapable of implementing efficiency, regardless of whether the public good is financed directly from tax revenue (and is, therefore, a function of individual consumption) or is provided independently of tax revenue.

2.2 Voluntary contributions with or without a sales tax are inefficient. Suppose that we allow for voluntary private monetary contributions $g_{i}$ to the public good in addition to the sales tax $\alpha \geq 0$. If, first, the public good is provided at the efficient level, $G^{*}$, regardless of tax revenue and

\footnotetext{
${ }_{14}$ Nevertheless, $\alpha$ can generally be chosen such that tax revenue covers the cost of the first-best level of the public good, $C\left(G^{*}\right)$.
} 
contributions, then the individually rational contribution is obviously $g_{i}=0$ and the result is similar to the case without private contributions. Second, if the public good's provision level depends on tax revenue and total contributions, then player $i$ maximises $w+v\left(x_{i}, G\right)-(1+\alpha) p x_{i}-g_{i}$, s.t. $C(G)=\sum_{j=1}^{n}\left(\alpha p x_{j}+g_{j}\right)$. The first-order condition with respect to $g_{i}$ is then $v_{G}=C^{\prime}(G)$. Thus, by comparison with (3), efficiency cannot be achieved for $n>1 .{ }^{15}$ Note that, in both cases, the conclusion is the same if $\alpha=0$.

2.3 A sales tax combined with a 'simple' lottery is inefficient. In the following, we look at a tax lottery scheme that is similar to the one we are going to analyse, except for the type of lottery employed. We show here that a 'simple' lottery does not serve the purpose. Under this scheme, consumers pay a sales tax through which the public good is financed. In order to encourage consumption (correcting the distortion due to the sales tax) we reward consumers with the chance to win a prize (or, in an equivalent interpretation, with a consumption-dependent share of the collected taxes). This prize or share is financed out of tax revenue.

Denote the sales tax revenue by $P=\alpha p \sum_{j=1}^{n} x_{j}$. Suppose that the share $\beta \in(0,1)$ of this tax revenue is paid out as the winner's prize of a 'simple' lottery where each player's probability of winning, $\pi_{i}$, is equal to his share of total sales tax contributions, or, equivalently, his share of total consumption, $\pi_{i}(\mathbf{x})=\left(\alpha p x_{i}\right) / \sum_{j=1}^{n}\left(\alpha p x_{j}\right)=x_{i} / \sum_{j=1}^{n} x_{j}{ }^{16}$ First, suppose that the public good is provided at the efficient level, $G^{*}$, regardless of tax revenue. Then utility is

$$
\begin{aligned}
u_{i} & =w+v\left(x_{i}, G^{*}\right)-(1+\alpha) p x_{i}+\pi_{i}(\mathbf{x}) \beta P, \quad \text { s.t. } P=\alpha p \sum_{j=1}^{n} x_{j} \\
& =w+v\left(x_{i}, G^{*}\right)-(1+\alpha) p x_{i}+\beta \alpha p \sum_{j=1}^{n} x_{j} . \\
& =w+v\left(x_{i}, G^{*}\right)-(1+(1-\beta) \alpha) p x_{i}
\end{aligned}
$$

Comparing (11) with (6) makes clear that the simple tax lottery is equivalent to a sales tax mechanism with tax rate $(1-\beta) \alpha$, which has been shown to be inefficient above.

Second, suppose that the public good is provided from the share of tax revenue that is not paid out to the lottery winner, $C(G)=(1-\beta) P$. Then player $i$ maximises

$$
\begin{aligned}
u_{i} & =w+v\left(x_{i}, G\right)-(1+\alpha) p x_{i}+\pi_{i}(\mathbf{x}) \beta P, \quad \text { s.t. } G=C^{-1}((1-\beta) P), P=\alpha p \sum_{j=1}^{n} x_{j} \\
& =w+v\left(x_{i}, C^{-1}\left((1-\beta) \alpha p \sum_{j=1}^{n} x_{j}\right)\right)-(1+(1-\beta) \alpha) p x_{i} .
\end{aligned}
$$

Again, this is similar to a sales tax mechanism with tax rate $(1-\beta) \alpha$ (see (9) for comparison). As we show in the main part of the paper, a more powerful, 'generalised' contest is required that sets

\footnotetext{
15 The classic reference is Bergstrom, Blume, and Varian (1986).

16 The adjective 'simple' refers to the fact that the probability of winning equals a player's share of total lottery tickets. As will become clear shortly, our tax lotteries require more sophisticated lotteries.
} 
stronger marginal incentives. ${ }^{17}$

\subsection{Private contributions combined with a simple lottery are inefficient (no sales tax).}

Instead of levying a sales tax and rewarding private consumption through a lottery, one might turn to using direct private contributions to the public good (as in 2.2) and reward these contributions through a lottery, financed from a part of total contributions.

Suppose that there is no sales tax and the only source of revenue for the government are voluntary private monetary contributions, $\mathbf{g}=\left(g_{1}, \ldots, g_{n}\right), g_{i} \geq 0$. Incentives for contributions are set through a simple lottery where each contributor $i$ 's winning probability is equal to his share of total contributions, $\pi_{i}(\mathbf{g})=g_{i} / \sum_{j=1}^{n} g_{j}$. The share $\gamma \in(0,1)$ of total contributions is paid out as a winner's prize while the remaining share is retained by the government in order to contribute to the cost of the public good. First, suppose that the government provides the efficient level of the public good regardless of players' contributions. Then player $i$ 's utility is

$$
\begin{aligned}
u_{i} & =w+v\left(x_{i}, G^{*}\right)-p x_{i}-g_{i}+\pi_{i}(\mathbf{g}) \gamma \sum_{j=1}^{n} g_{j} \\
& =w+v\left(x_{i}, G^{*}\right)-p x_{i}-(1-\gamma) g_{i} .
\end{aligned}
$$

Clearly, $i$ 's optimal contribution is $g_{i}^{*}=0$, since $i$ 's net benefit from the lottery is negative, regardless of the other players' contributions. Thus, the mechanism does not raise any money. (In 2.5 we give another argument that also applies here.)

Second, suppose that the government finances the public good entirely from the part of players' contributions that is not paid out as a prize, i.e., $C(G)=(1-\gamma) \sum_{j=1}^{n} g_{j}$. In this case, the above argument does not apply because now there is an additional benefit from contributions: they directly raise the level of the public good. Utility is

$$
\begin{aligned}
u_{i} & =w+v\left(x_{i}, C^{-1}(C(G))\right)-p x_{i}-g_{i}+\overbrace{\pi_{i}(\mathbf{g}) \gamma \sum_{j=1}^{n} g_{j}}^{=\gamma g_{i}}, \quad \text { s.t. } G=C^{-1}\left((1-\gamma) \sum_{j=1}^{n} g_{j}\right) \\
& =w+v\left(x_{i}, C^{-1}\left((1-\gamma) \sum_{j=1}^{n} g_{j}\right)\right)-p x_{i}-(1-\gamma) g_{i} .
\end{aligned}
$$

The first-order condition with respect to $g_{i}$ can be written as marginal utility of the public good equals marginal cost of the contribution, net of the lottery benefit,

$$
\frac{v_{G}}{C^{\prime}(G)}(1-\gamma)=(1-\gamma) \quad \Longleftrightarrow \quad v_{G}=C^{\prime}(G)
$$

Similar to 2.3 , the net marginal cost of $i$ 's contribution (net of the lottery benefit) is constant, $1-\gamma$.

\footnotetext{
17 This subsection extends a result by Morgan (2000) who shows that a simple lottery cannot achieve efficiency in a model with private contributions to a public good. Our analysis shows that the simple lottery is a knife-edge case, because many efficient contest mechanisms exist, that is, mechanisms where the winning probabilities feature 'increasing returns' to scale. This seems to correspond to reality: Prominent examples exist-for instance in the German or Austrian Klassenlotterien-where purchasing a higher 'class' ticket increases winning chances (or prizes) disproportionately. For a detailed description of these institutions see Schönbein (2008). Moreover, the sale of 'bulk tickets' at a discount is a common way of increasing lottery revenue. We are grateful to Martin Kolmar for pointing out this interpretation of the disproportionality in the winning probability.
} 
But this net cost is too large, in the sense that it 'forces' $i$ to choose an inefficient contribution: $v_{G}=C^{\prime}(G)$ violates (3). As in 2.3, this would be efficient for $n=1$, illustrating the free-rider problem. Player $i$ ignores the benefit of his contribution for the other players. ${ }^{18}$

2.5 Private contributions with a generalised lottery are inefficient (no sales tax) . We stay in the same environment as in the previous subsection 2.4. We have seen that a simple lottery does not achieve efficiency. Thus, we now consider a generalised contest form instead where $i$ 's probability of winning is $\pi_{i}(\mathrm{~g})$, and, if contributions are symmetric, $g_{1}=\cdots=g_{n}$, the winning probability is $1 / n$, while everything else remains the same as in 2.4. First, suppose that the public good is provided exogenously at the efficient level, $G^{*}$. Player $i$ 's expected utility is

$$
u_{i}=w+v\left(x_{i}, G^{*}\right)-p x_{i}-g_{i}+\pi_{i}(\mathbf{g}) \gamma \sum_{j=1}^{n} g_{j}
$$

This mechanism cannot implement efficiency because the only reason for participation in the lottery is the chance of winning the prize money. But the prize money is only a share of total contributions. Since, in any symmetric equilibrium (candidate), with contributions equal to $g$, the winning probability is $1 / n$, player $i$ 's expected lottery payoff is $(1 / n) \gamma n g$ which is less than $i$ 's contribution. Thus, $i$ 's optimal contribution is $g^{*}=0$. (The same argument shows that exogenous provision is inefficient in 2.4.)

Second, suppose that the government always balances its budget, spending exactly the share $(1-\gamma)$ of contributions on the public good. Similar to the first setup, the lottery itself is not 'interesting' for $i$, since, in any symmetric equilibrium, it pays out less in expectation than $i$ pays for it. Thus, the endogenous-provision scheme as a whole can only work if $i$ 's benefit from the public good can make up for this 'loss'. Indeed, $i$ 's contribution has a direct benefit in the form of a larger amount of the public good. However, this setup also brings about a free-rider problem because $i$ also benefits from the other $n-1$ players' contributions. In fact, if $i$ deviates from an efficient contribution to zero $g_{i}=0$ (given that the other $n-1$ players contribute efficiently), then $i$ 's cost saving exceeds the 'loss' due to a reduced amount of the public good. In order to see why, note that if $i$ were the only player in the economy $(n=1), i$ would equalise the slopes of utility and cost, $v_{G}=C^{\prime}(G)$. In a larger economy, by the Samuelson condition, efficiency requires a larger amount of the public good, such that the slope of the utility function is smaller than that of the cost function, $n v_{G}=C^{\prime}\left(G^{*}\right)$, see (3). Now, suppose that $i$ reduces his contribution, implying a move from $G=G^{*}$ to a lower amount of the public good. Then, due to the slopes, the total cost reduction is larger than the utility loss of a single player. Since $i$ receives the full cost saving, the deviation is profitable. The following proposition shows that this insight is perfectly general.

\footnotetext{
18 This corresponds to a similar result in Morgan (2000), showing that a simple lottery with private contributions cannot implement efficiency in the absence of a private good. He also analyses 'fixed-prize raffles,' where a fixed prize $R$ is awarded to the contest winner. That prize is financed by the players' contributions, such that the amount of the public good is $G=\sum_{j=1}^{n} g_{j}-R$ with cost of $C(G)=G$ (in our notation). Such a scheme cannot induce efficiency in our setting, either.
} 
Proposition 1. Suppose that the public good is provided endogenously, from a share of voluntary private contributions. Then there exists no efficient symmetric pure-strategy equilibrium under a contributions scheme with a generalised contest.

\section{The tax lottery scheme}

In order to overcome the problems outlined in the previous section, we introduce the following tax lottery scheme. ${ }^{19}$ A sales tax of proportion $\alpha>0$ is collected from the private good consumption in order to form a revenue pool, $P=\alpha p \sum_{j=1}^{n} x_{j}$. The share $\beta$ of this pool is awarded as the winner's prize in a contest held on the purchased quantities of the private good. The share $(1-\beta)$ of this pool can be used to finance the public good. As before, the public good is either exogenously provided at $G=G^{*}$, resulting in the utility maximisation problem

$$
\max _{x_{i}} u_{i}=w+v\left(x_{i}, G^{*}\right)+\pi_{i}(\mathbf{x}) \beta P-(1+\alpha) p x_{i}, \quad \text { s.t. } P=\alpha p \sum_{j=1}^{n} x_{j}
$$

or the provision level depends on actual tax revenue, $C(G)=(1-\beta) P$, resulting in

$$
\max _{x_{i}} u_{i}=w+v\left(x_{i}, G\right)+\pi_{i}(\mathbf{x}) \beta P-(1+\alpha) p x_{i}, \quad \text { s.t. } P=\alpha p \sum_{j=1}^{n} x_{j}, G=C^{-1}((1-\beta) P),
$$

where $\pi_{i}(\mathbf{x})$ is player $i$ 's probability of winning the contest as a function of all players' private good consumption. ${ }^{20}$ We assume that the noisy (partial) ranking $\pi(\mathbf{x})=\left(\pi_{1}(\mathbf{x}), \ldots, \pi_{n}(\mathbf{x})\right)$ of the players' consumption expenditures is observable and verifiable. Moreover, $\pi_{i}(\mathbf{x})$ is strictly increasing in $x_{i}$, strictly decreasing in all other arguments, equal to $1 / n$ for identical arguments, twice continuously differentiable, and zero for $x_{i}=0$ if at least one $x_{j \neq i}>0, j \in \mathcal{N}$.

The designer's objective is to maximise the total sum of utilities net of the cost of producing the public good by choosing a tax lottery scheme $\left\langle\alpha^{*}, \beta^{*}, \pi(\mathbf{x})\right\rangle$ which allows for the efficient provision of the public good while simultaneously ensuring efficient private good consumption and balancing the government's budget.

\subsection{Example of an efficient tax lottery scheme}

This subsection presents an illustrative example of the tax lottery scheme. We use Cobb-Douglas preferences over the private and public goods, $v\left(x_{i}, G\right)=x_{i}^{a} G^{b}$, with $a, b>0, a+b<1$, where the public good is produced at linear cost, $C(G)=q G$ with $q>0 .{ }^{21}$

\footnotetext{
19 Our scheme relates to that analysed in 2.3 , but differs in the precise formulation of winning probabilities.

20 Note that in our symmetric setup it does not matter whether the winning probability is determined from consumption quantities $x_{i}$ or from a player's sales tax contribution $\alpha p x_{i}$ because the common factor $\alpha p$ cancels out under the assumptions we make on the lottery mechanism, see subsection 5.4.

21 A similar example works for additive separable preferences. Since the fully separable case is known to lend itself to efficient public goods provision (under conditions discussed, for instance, by Deaton (1981) or Bergstrom and Cornes (1983)), we use Cobb-Douglas preferences as our leading example. This, however, leads to sometimes unwieldy expressions which could be avoided in the quasilinear case.
} 
The resulting social planner's problem is concave and given by

$$
\left(\mathbf{x}^{*}, G^{*}\right)=\underset{x, G}{\operatorname{argmax}} \sum_{j=1}^{n}\left(w+x_{j}^{a} G^{b}-p x_{j}\right)-q G .
$$

The efficient (symmetric) quantities $x^{*}=x_{1}^{*}=\cdots=x_{n}^{*}$ and $G^{*}$, see (3) and (4), are positive and unique,

$$
x^{*}=\left(\frac{a}{p}\right)^{\frac{1-b}{1-a-b}}\left(\frac{n b}{q}\right)^{\frac{b}{1-a-b}}, \quad G^{*}=\left(\frac{a}{p}\right)^{\frac{a}{1-a-b}}\left(\frac{n b}{q}\right)^{\frac{1-a}{1-a-b}} .
$$

Now consider the tax lottery scheme. For the lottery, we use the generalised Tullock contest success function,

$$
\pi_{i}(\mathbf{x})=\frac{x_{i}^{r}}{\sum_{j=1}^{n} x_{j}^{r}}, \quad r>0
$$

with $\pi_{i}(\mathbf{x})=1 / n$ if $x_{1}=x_{2}=\cdots=x_{n}=0 .{ }^{22}$ The exponent $r$ can be interpreted as the 'discriminatory power,' or 'precision' of the lottery defining the (marginal) increase in the (marginal) probability of winning from higher consumption of the private good.

Recall that the sales tax revenue is given by $P=\alpha p \sum_{j=1}^{n} x_{j}$. The share $(1-\beta)$ is used to finance the public good, $G$, while the remaining share, $\beta$, is paid out as the winner's prize in the contest. Each consumer of the private good participates in the lottery.

As in the taxonomy of alternative approaches in the previous section, we consider two ways of providing the public good. First, it is provided exogenously at the efficient level, $G^{*}$, and, second, the provision level depends on the actual tax revenue. Our central result is that for both ways of providing the public good, there exists a corresponding optimal tax lottery scheme $\left\langle\alpha^{*}, \beta^{*}, r\right\rangle$ which induces a symmetric equilibrium in which every player $i \in \mathcal{N}$ consumes the efficient quantity of the private good $x^{*}$ while the public good is provided in the efficient amount $G^{*}$ and the government's budget is balanced.

First, suppose that the government provides the public good exogenously. Then player $i$ 's maximisation problem is

$$
\max _{x_{i}} u_{i}=w+x_{i}^{a} G^{b}+\frac{x_{i}^{r}}{\sum_{j=1}^{n} x_{j}^{r}} \beta P-(1+\alpha) p x_{i} \quad \text { s.t. } P=\alpha p \sum_{j=1}^{n} x_{j},
$$

where $G$ is constant at $G=G^{*}$. Take the first derivative with respect to $x_{i}$, and impose symmetry $x=x_{i}=x_{j}$ in the first-order condition. Then replace $G$ and $x$ by the efficient levels, $G^{*}$ and $x^{*}$. This delivers $\beta^{*}$. Then compute $\alpha^{*}$ by solving the government's budget constraint using $G=G^{*}$, $x=x^{*}$ and $\beta=\beta^{*}$, i.e., $q G^{*}=\left(1-\beta^{*}\right) \alpha p n x^{*}$. Following this procedure, we obtain

$$
\alpha^{*}=\frac{b}{a} \frac{1+(n-1) r}{(n-1)(r-1)}, \quad \beta^{*}=\frac{n}{1+r(n-1)} .
$$

\footnotetext{
22 The Tullock success function has been axiomatised by Skaperdas (1996) and others who show that only variants of the Tullock contest success function satisfy a set of desiderata similar to our assumptions in section 5.4. Fu and Lu (2012) and Jia (2008) derive distribution-based foundations for the general Tullock formulation.
} 
Second, suppose that the public good is financed from tax revenue. Then (21) must satisfy the additional constraint $q G=(1-\beta) P$, the government budget constraint. Start with evaluating this budget constraint at the efficient levels, $x^{*}$ and $G^{*}$. This gives directly

$$
\alpha=\frac{b}{a(1-\beta)}
$$

Then the optimal tax lottery scheme is determined by inserting $q G=(1-\beta) P$ as well as $P=$ $\alpha p \sum_{j=1}^{n} x_{j}$ into the objective function (21), computing the first derivative with respect to $x_{i}$, imposing symmetry, $x=x_{i}=x_{j}$ in the first-order condition and then replacing $x$ by the efficient amount, $x^{*}$. Inserting $\alpha$ from (23) gives the optimal scheme

$$
\alpha^{*}=\frac{b}{a} \frac{r}{r-1}, \quad \beta^{*}=\frac{1}{r} .
$$

In both cases, feasibility, i.e., $\beta^{*} \in(0,1)$, is satisfied if $r>1$ while $\alpha^{*}>0$ is then assured. Notice that, in (24), the designer has a degree of freedom. We expressed the optimal $\alpha^{*}$ and $\beta^{*}$ as functions of $r$. Alternatively, the optimal tax lottery scheme can be tailored to an exogenously given sales tax, $\alpha$.

As is apparent from (24), higher values of $r$, i.e., a more competitive lottery, are associated with smaller tax rates $\alpha^{*}$ and a smaller share $\beta^{*}$ of tax revenue to be used as lottery prize. Comparing (22) with (24), it is easy to see that the second scheme, with endogenous provision of the public good, requires a lower sales tax rate and a lower share of revenue for the contest. This is because, under endogenous provision, private consumption has an additional private benefit: it directly raises the provision level of the public good and, thus, utility. In both cases, the government's budget is balanced in equilibrium.

In the above, we only looked at the first-order condition of utility maximisation in an efficient candidate equilibrium. As we have already seen in subsection 2.1, satisfying the first-order condition may not, however, be sufficient. There, participation in the symmetric candidate was strictly dominated by nonparticipation.

Under our tax lottery scheme, nonparticipation is not an issue, since the contest is run on private consumption rather than monetary contributions. Thus, nonparticipation would imply zero private consumption which clearly is not optimal. Nevertheless, in contrast to the simple lottery, the use of more general lotteries, such as the generalised Tullock contest, does not generally imply a concave objective (utility) function. Thus, existence of the optimal scheme is not guaranteed for all parameters. The following figure explores the question of equilibrium existence for our example by plotting $i$ 's single-peaked equilibrium deviation utility arising from different consumption levels $x_{i}$ under the tax lottery scheme with $\alpha^{*}$ and $\beta^{*}$, assuming that every player $j \neq i$ chooses the equilibrium $x_{j}=x^{*}{ }^{23}$ The participation issue in subsection 2.5 already indicates that equilibrium

\footnotetext{
23 The parameters used for plotting the figure are $n=2, p=q=1, a=3 / 4, b=1 / 10, r=2, x^{*}=0.0601$, $g^{*}=0.0081, \alpha^{*}=0.73, \beta^{*}=0.5$, and endogenous provision of the public good. We should also point out that there is a long-standing issue with the existence of symmetric pure strategy equilibria when $r>1$ in standard contests with many players (see, e.g., Schweinzer and Segev (2012)). As shown in propositions 2 and 3, however, existence conditions are not as restrictive in the present environment.
} 


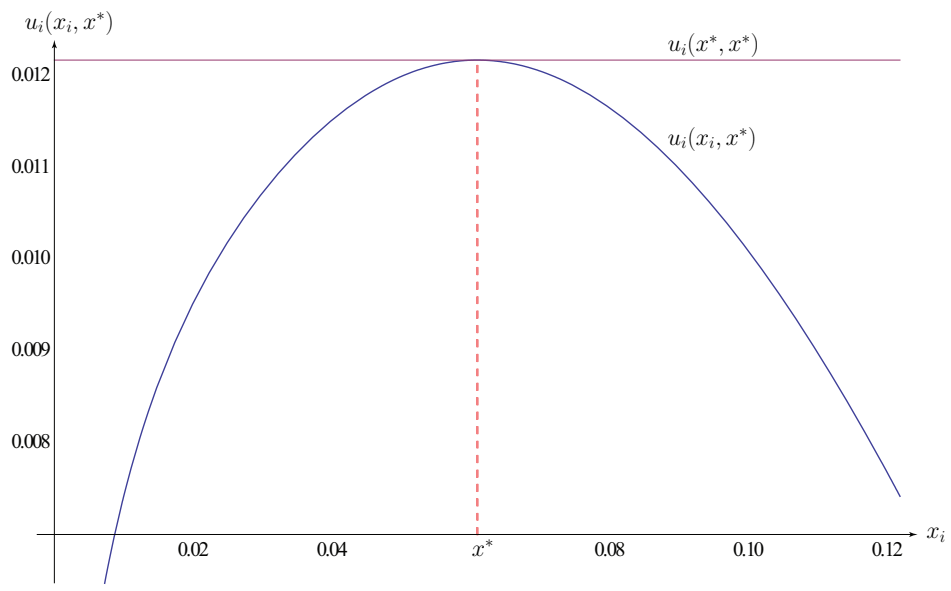

Figure 1: Private good consumption levels ensuring efficient public good provision.

existence in this setting is not only a question of whether the solution candidate picks out a local maximum or minimum. We need to ensure that the candidate is globally optimal. Figure 1 attempts to illustrate the problem graphically. For this to be convincing, in principle, we would have to plot the full choice range $x_{i} \in[0, \infty)$ given $x_{j}=x^{*}, j \neq i$. In this sense, the above picture should be understood to only show the interesting range.

This simple example demonstrates that a sales tax, accompanied by an appropriately designed generalised Tullock contest is capable of simultaneously implementing efficiency in the private as well as the public good dimensions and, thus, satisfying the Samuelson condition while balancing the government's budget. We have further shown that the obtained efficiency does not depend on whether the public good is provided exogenously or depending on actual tax revenue. Propositions 2 and 3 show formally that this example result holds for a broad range of parameters. The following section presents a general analysis and sheds light on why this scheme, in contrast to those presented in 2.5, can achieve efficiency.

\section{Analysis of the tax lottery scheme}

In order to simplify the exposition, we present the analysis for the generalised ratio-based contest form

$$
\pi_{i}(\mathbf{x})=\frac{f\left(x_{i}\right)}{\sum_{j=1}^{n} f\left(x_{j}\right)}
$$

where $f^{\prime}>0$ and $f(0)=0$ and $f(x)>0$ if $x>0$ (further restrictions on $f$ will be derived for the optimal scheme). Our results, however, hold for a wider range of contest specifications, some of which we explore in section 5.

First, consider the case of exogenous provision of the public good at $G=G^{*}$. Maximising utility, (16), the first-order condition can be written as

$$
v_{x}+\left(\frac{\partial \pi_{i}(\mathbf{x})}{\partial x_{i}} \sum_{j=1}^{n} x_{j}+\pi_{i}(\mathbf{x})-\frac{1}{\beta}\right) \beta \alpha p=p .
$$


Again, efficiency in the private good dimension requires that the above parenthesis vanish, i.e.,

$$
\frac{f^{\prime}\left(x_{i}\right) \sum_{j \neq i} f\left(x_{j}\right)}{\left(\sum_{j=1}^{n} f\left(x_{j}\right)\right)^{2}} \sum_{j=1}^{n} x_{j}+\frac{f\left(x_{i}\right)}{\sum_{j=1}^{n} f\left(x_{j}\right)}=\frac{1}{\beta}
$$

In symmetric equilibrium, where all players consume, say, $x_{s}$, this simplifies to

$$
\begin{aligned}
& \frac{f^{\prime}\left(x_{s}\right)(n-1) f\left(x_{s}\right)}{\left(n f\left(x_{s}\right)\right)^{2}} n x_{s}+\frac{f\left(x_{s}\right)}{n f\left(x_{s}\right)}=\frac{1}{\beta} \\
& \Longleftrightarrow \quad \frac{f^{\prime}\left(x_{s}\right)(n-1) x_{s}+f\left(x_{s}\right)}{n f\left(x_{s}\right)}=\frac{1}{\beta} \\
& \Leftrightarrow \quad \\
& \beta=\frac{n f\left(x_{s}\right)}{f^{\prime}\left(x_{s}\right)(n-1) x_{s}+f\left(x_{s}\right)} .
\end{aligned}
$$

Feasibility requires $\beta<1$, i.e.,

$$
\begin{aligned}
n f\left(x_{s}\right) & <f^{\prime}\left(x_{s}\right)(n-1) x_{s}+f\left(x_{s}\right) \\
\Longleftrightarrow \quad(n-1) f\left(x_{s}\right) & <f^{\prime}\left(x_{s}\right)(n-1) x_{s} \\
\Longleftrightarrow \quad f\left(x_{s}\right) & <f^{\prime}\left(x_{s}\right) x_{s} .
\end{aligned}
$$

Clearly, this last condition is violated under the simple lottery, where $f\left(x_{s}\right)=x_{s}=f^{\prime}\left(x_{s}\right) x_{s}$, confirming the result of subsection 2.3. Thus, an efficient tax lottery requires a function $f$ that can satisfy this condition. One such function is the generalised Tullock contest, with $f(x)=x^{r}$ and $r>0$. Inserted into (29), we get

$$
x_{s}^{r}<r x_{s}^{r-1} x_{s} \Longleftrightarrow r>1
$$

Thus, for $r>1$, the function $f(x)=x^{r}$ implements efficient private consumption (ignoring equilibrium existence for the moment). Inserting $f\left(x_{s}\right)=x_{s}^{r}$ into (28), we get

$$
\beta^{*}=\frac{1}{1+r(n-1)} \in(0,1)
$$

Note that $\beta^{*}$ only depends on $r$ (the 'discriminatory power' of the lottery) and the number of players. Since $G=G^{*}$ is ensured, what remains to be done is to compute the sales tax that balances the government's budget, i.e., solve $C\left(G^{*}\right)=(1-\beta) \alpha p n x_{s}$ taking into account the above value of $\beta=\beta^{*}$, as well as the fact that consumption is efficient, $x_{s}=x_{i}^{*}$ (as derived above). This optimal share $\alpha$ is given by

$$
C\left(G^{*}\right)=\left(1-\beta^{*}\right) \alpha p n x_{i}^{*} \quad \Longleftrightarrow \quad \alpha^{*}=\frac{C\left(G^{*}\right) / n}{p x_{i}^{*}} \frac{1}{1-\beta^{*}} .
$$

So far, we have only considered the first-order condition(s) for efficiency. The following proposition confirms equilibrium existence for a class of non-separable utility functions for a public good produced at linear cost. (A discussion of why this scheme works will be given after the analysis of the 
endogenous provision setting.)

Proposition 2. Consider the class of Cobb-Douglas utility, $v\left(x_{i}, G\right)=x_{i}^{a} G^{b}$ with $a, b>0, a+b<1$, and linear cost of the public good, $C(G)=q G$ with $q>0$ and suppose that the government provides the public good at the efficient level independently of tax revenue. For any $r>1$ and sufficiently small $b$, there exists a tax lottery scheme $\left\langle\alpha^{*}, \beta^{*}, r\right\rangle$, using a Tullock contest, $\pi_{i}(\mathbf{x})=x_{i}^{r} / \sum_{j=1}^{n} x_{j}^{r}$, that implements efficiency in symmetric pure-strategy Nash equilibrium.

Now, consider the case where the public good is financed from the share of tax revenue that is not paid out to the lottery winner, i.e., the government budget constraint is $C(G)=(1-\beta) \alpha p \sum_{j=1}^{n} x_{j}$. Then player $i$ maximises (17) with winning probability $\pi_{i}(\mathbf{x})=\frac{f\left(x_{i}\right)}{\sum_{j=1}^{n} f\left(x_{j}\right)}$. The first-order condition with respect to $x_{i}$ is

$$
v_{x}+\frac{v_{G}}{C^{\prime}(G)}(1-\beta) \alpha p-(1+\alpha) p+\frac{f^{\prime}\left(x_{i}\right) \sum_{j \neq i} f\left(x_{j}\right)}{\left(\sum_{j=1}^{n} f\left(x_{j}\right)\right)^{2}} \sum_{j=1}^{n} x_{j} \beta \alpha p+\frac{f\left(x_{i}\right)}{\sum_{j=1}^{n} f\left(x_{j}\right)} \beta \alpha p=0
$$

This can be written as

$$
v_{x}+\left(\frac{v_{G}}{C^{\prime}(G)}(1-\beta)+\frac{f^{\prime}\left(x_{i}\right) \sum_{j \neq i} f\left(x_{j}\right)}{\left(\sum_{j=1}^{n} f\left(x_{j}\right)\right)^{2}} \sum_{j=1}^{n} x_{j} \beta+\frac{f\left(x_{i}\right)}{\sum_{j=1}^{n} f\left(x_{j}\right)} \beta-1\right) \alpha p=p .
$$

In symmetric equilibrium where every player consumes the same quantity, say, $x_{s}$, this simplifies to

$$
v_{x}+\left(\frac{v_{G}}{C^{\prime}(G)}(1-\beta)+\frac{f^{\prime}\left(x_{s}\right)(n-1)}{n f\left(x_{s}\right)} x_{s} \beta+\frac{1}{n} \beta-1\right) \alpha p=p .
$$

Efficiency in the public good dimension requires (3). Thus, we replace $\frac{v_{G}}{C^{\prime}(G)}$ above by $1 / n$. Efficiency in the private good dimension requires that the parenthesis in the above expression is then equal to zero. Thus, we need to satisfy

$$
\frac{1}{n}(1-\beta)+\frac{f^{\prime}\left(x_{s}\right)(n-1)}{n f\left(x_{s}\right)} x_{s} \beta+\frac{1}{n} \beta-1=0,
$$

which simplifies to

$$
\beta=\frac{f\left(x_{s}\right)}{f^{\prime}\left(x_{s}\right) x_{s}}
$$

Feasibility requires that the function $f$ enables $\beta \in(0,1)$. Again, consider the generalised Tullock contest, $f\left(x_{s}\right)=x_{s}^{r}$. In this case we obtain

$$
\beta^{*}=\frac{1}{r}
$$

which is feasible, i.e., $\beta^{*} \in(0,1)$ if and only if $r>1$. This demonstrates, that $f\left(x_{s}\right)=x_{s}^{r}$ with $r>1$ implements efficiency in both dimensions, i.e., we obtain provision and consumption levels of $G^{*}$ and $x_{i}^{*}$, respectively. We can now compute the sales tax rate that balances the government's 
budget, $C\left(G^{*}\right)=\left(1-\beta^{*}\right) \alpha p n x_{i}^{*}$,

$$
\alpha^{*}=\frac{C\left(G^{*}\right) / n}{p x_{i}^{*}} \frac{1}{1-\beta^{*}}
$$

Again, we provide an existence result for a class of utility functions and linear cost.

Proposition 3. Consider the class of Cobb-Douglas utility, $v\left(x_{i}, G\right)=x_{i}^{a} G^{b}$ with $a, b>0, a+b<1$, and linear cost of the public good, $C(G)=q G$ with $q>0$ and suppose that the public good's provision level depends on tax revenue, $C(G)=(1-\beta) P$. For any $r>1$ and sufficiently small $b$, there exists a tax lottery scheme $\left\langle\alpha^{*}, \beta^{*}, r\right\rangle$ using a Tullock contest, $\pi_{i}(\mathbf{x})=x_{i}^{r} / \sum_{j=1}^{n} x_{j}^{r}$, that implements efficiency in symmetric pure-strategy Nash equilibrium.

In order to illustrate that equilibrium existence does not require infinitesimal values of $b$, figure 2 plots player $i$ 's utility as a function of the consumption level $x_{i}$, given endogenous provision of the public good, $a=0.25, p=q=1, n=10, r=2, \alpha=\alpha^{*}, \beta=\beta^{*}$ and $x_{j}=x^{*}, j \neq i$. The upper curve represents $b=0.45$ which is too large, inducing a local minimum at $x_{i}=x^{*}$. The lower curve represents $b=0.05$ which is strictly less than what is required for existence. As $b$ is decreased from 0.45 to smaller values, the objective (utility) function becomes more concave. The critical value of $b$, below which existence is ensured, can be numerically determined to be 0.115 and 0.105 in the endogenous and exogenous provision cases, respectively. ${ }^{24}$

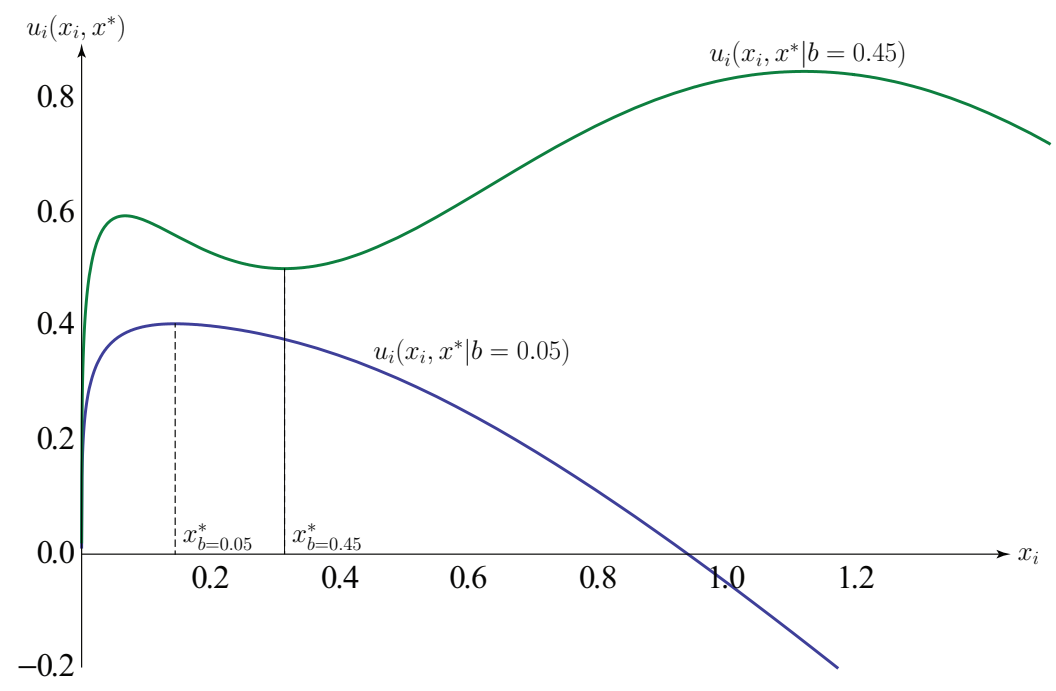

Figure 2: Equilibrium existence under endogenous provision of the public good and Cobb-Douglas parameter $b \in\{0.05,0.45\}$ for the public good.

As already mentioned in subsection 3.1, nonparticipation is not an issue here (in contrast to the voluntary contributions schemes) since zero consumption is never optimal. This is confirmed by Figure 2.

In the following we want to shed more light on the question why the tax lottery scheme achieves efficiency, whereas the alternative mechanisms discussed in subsections 2.1-2.5 cannot. We mainly

\footnotetext{
24 The precise procedure is described in the proofs of propositions 2 and 3.
} 
want to compare our scheme with the voluntary contributions scheme in subsection 2.5 (endogenous provision), since that is the only scheme where efficiency does not already fail at the first-order condition.

First, note that the tax lottery scheme builds on a sales tax mechanism. As recalled in subsection 2.1, a sales tax in itself is capable of financing the public good, although it distorts consumption. Thus, in contrast to the voluntary contributions scheme in subsection 2.5., the lottery in our scheme 'only' needs to give incentives to consume more (correcting the distortion) while balancing the government's budget. Second, as mentioned above, nonparticipation is not a viable option under the tax lottery scheme, indicating that only a correction in consumption (at the margin) is necessary, rather than ensuring that the scheme as a whole attracts participation. Third, as we have seen in subsection 2.4, a simple lottery is 'too weak' in the sense that the marginal incentives it provides are insufficient to fully correct the distortion in consumption (regardless of whether there is a free-rider problem, as in the endogenous provision case). A generalised lottery, as considered above, however, can be designed to provide higher incentives at the margin (e.g., varying $r$ in a Tullock contest), and therefore correcting underconsumption (in principle raising any amount of money, such that only participation might be a problem). In particular, in our first case of exogenous provision, the lottery's task is to correct the distortion in private consumption while at the same time raising revenue equal to the cost of the efficient level of the public good (after paying for the lottery itself). In the second case of endogenous provision, the same reasoning applies with an additional effect: consumption directly raises the level of the public good. At the margin, this increases the utility from private consumption, making it easier to satisfy the first-order condition (as we have shown, for a given lottery this results in a lower sales tax rate $\alpha^{*}$ as well as a lower prize $\beta^{*}$ necessary for efficient implementation).

Of course, the endogenous provision case introduces a free-rider problem. But, compared to the exogenous provision case, this free-rider problem can only cause existence problems, similar to those in subsection 2.5. However, in contrast to subsection 2.5, under the tax lottery scheme, there is a countervailing effect: The private consumption decision has a direct utility as well as a price, regardless of the tax lottery scheme (and exogenous or endogenous provision of the public good). This makes 'extreme' decisions less attractive, since any action geared towards changing one's payoff from the tax lottery scheme, e.g., consuming less in order to save money (while possibly free-riding on other's actions, as in the endogenous provision case) or consuming extreme amounts in order to raise one's lottery payoff, distorts the balance between the utility of consumption and its cost. Consuming too little reduces the utility from the private good, consuming too much has to be paid for in terms of the price $p$ as well as the sales tax $\alpha$.

This effect is missing in the private contributions scheme and even a generalised lottery cannot correct this (subsection 2.5), while in a tax lottery scheme with a simple lottery, the lottery itself is not powerful enough (subsection 2.3). Only the combination of a sales tax and a generalised lottery can implement efficiency (among the mechanisms we have studied). Our existence results in propositions 2 and 3 underscore that the balance between utility from the private good (and its cost) and utility from the tax lottery scheme (i.e., the lottery itself and, in the endogenous 
provision case, the severity of the free-rider problem) is crucial. As these proofs show, the CobbDouglas utility parameter for the public good must be sufficiently small in order to ensure equilibrium existence. Similarly, existence is unproblematic if there are sufficiently many players such that player $i$ 's (consumption) decision's effect on his utility from the lottery, resp. the public good, is less relevant than its direct effect on utility from the private good and its associated cost (from buying the good in the market). All in all, the utility and cost of private consumption must be sufficient to ensure that manipulating consumption in favour of lottery payoff or the public good is not worth a player's while.

\section{Extensions}

We now present several model extensions illuminating the robustness of the tax lottery mechanism. We only present results for the endogenous provision case of the public good here because we economise on space. This case is generally more complicated than the case of exogenous provision since, there, the individual decision has no effect on the public good's provision level. Moreover, we employ the generalised Tullock contest success function for the tax lottery mechanism and assume a linear cost of the public good production. We mostly ignore consumer wealth levels for reasons of brevity.

\subsection{Asymmetric Players}

In this subsection we show that the efficiency we derived for the identical players case extends to heterogeneous consumers, provided that the designer can apply individualised instruments, i.e., personalised tax rates $\alpha_{i}, i \in \mathcal{N}$. We model player heterogeneity through individual utility functions $v_{i}\left(x_{i}, G\right)$. As usual, we denote the efficient quantities by $\mathbf{x}^{*}=\left(x_{1}^{*}, \ldots, x_{n}^{*}\right)$ and $G^{*}$.

In our symmetric model with homogeneous preferences, using the consumed quantities $x_{i}$ in the contest success function is equivalent to entering the consumer's (symmetric) sales tax contribution $\alpha p x_{i}$. In the present heterogeneous case, however, this is no longer the case, and, in line with our motivating examples, we now assume that a player's monetary contribution (the consumer's sales tax paid) rather than the quantity consumed, enters the success function. Thus, player $i$ 's winning probability in the tax lottery with individual tax rates is

$$
\left(\alpha_{i} p x_{i}\right)^{r} / \sum_{j=1}^{n}\left(\alpha_{j} p x_{j}\right)^{r}=\left(\alpha_{i} x_{i}\right)^{r} / \sum_{j=1}^{n}\left(\alpha_{j} x_{j}\right)^{r} .
$$

In order to be able to derive explicit solutions, we employ a logarithmic transformation of our previously used Cobb-Douglas utility function in which we assume that consumers differ in their preferences for the private good: ${ }^{25}$

$$
u_{i}=a_{i} \log \left(x_{i}\right)+b \log (G) .
$$

\footnotetext{
25 This allows for an analytic solution to the planner's asymmetric problem which is unavailable for the untransformed Cobb-Douglas formulation. The numerical solutions to our tax lottery mechanism are available for both preference specifications.
} 
Social welfare maximisation analogous to (18) results in the efficient benchmark bundle

$$
x_{i}^{*}=\frac{a_{i}}{p}, G^{*}=\frac{n b}{q}, \quad \forall a_{i}, b>0 .
$$

As in the symmetric model, we develop the two-players case (on the basis of section 3.1) in the main text while the general result is derived in the corresponding proposition 4 . Suppose that the public good is provided endogenously, that is, $q G=(1-\beta) P$, where total tax revenue $P=\alpha_{1} p x_{1}+\alpha_{2} p x_{2}$. We demonstrate, on the basis of first-order conditions, that the mechanism

$$
\left\langle\alpha_{1}^{*}, \alpha_{2}^{*}, \beta^{*}, r\right\rangle=\left\langle\frac{A}{a_{1}}, \frac{A}{a_{2}}, \frac{1}{r}, r\right\rangle, \quad A=\frac{b r}{r-1},
$$

implements efficiency in symmetric pure-strategy equilibrium. ${ }^{26}$ Obviously, $r=1$ is not feasible. In (43), note that $A=\alpha_{1}^{*} a_{1}=\alpha_{2}^{*} a_{2}$ is constant. Provided that the efficient quantities are consumed, these tax rates make the lottery contest symmetric, i.e., players have the same probability of winning. ${ }^{27}$ Thus, individualised tax rates adjust a player's marginal cost $\left(\alpha_{i} p\right)$ in accordance with their individual marginal utility of private consumption.

Suppose that player 2 consumes the efficient amount $x_{2}^{*}=a_{2} / p$ which implies that 2 's contribution is $\alpha_{2}^{*} p x_{2}^{*}=\alpha_{2}^{*} p a_{2} / p=A$. Then player 1's objective is

$u_{1}=a_{1} \log \left(x_{1}\right)+b \log \left(\frac{(1-\beta)\left(\alpha_{1} p x_{1}+A\right)}{q}\right)-\left(1+\alpha_{i}\right) p x_{i}+\frac{\left(\alpha_{1} p x_{1}\right)^{r}}{\left(\alpha_{1} p x_{1}\right)^{r}+A^{r}} \beta\left(\alpha_{1} p x_{1}+A\right)$.

Player 1's (simplified) first-order condition with respect to $x_{1}$ is

$$
\frac{a_{1}}{x_{1}}+\frac{b \alpha_{1} p}{\alpha_{1} p x_{1}+A}-\left(1+\alpha_{1}\right) p+\frac{r\left(\alpha_{1} p x_{1}\right)^{r-1} \alpha_{1} p A^{r}}{\left(\left(\alpha_{1} p x_{1}\right)^{r}+A^{r}\right)^{2}} \beta\left(\alpha_{1} p x_{1}+A\right)+\frac{\left(\alpha_{1} p x_{1}\right)^{r}}{\left(\alpha_{1} p x_{1}\right)^{r}+A^{r}} \beta \alpha_{1} p=0 .
$$

Inserting the efficient quantity $x_{1}^{*}$, replacing $\alpha_{1} a_{1}$ with $A$, dividing by $\alpha_{i} p$, and simplifying, delivers

$$
\frac{b}{2 A}-1+\frac{r \beta}{2}+\frac{\beta}{2}=0 \quad \Longleftrightarrow \quad b=A(2-\beta(r+1))
$$

Budget balance, evaluated at the efficient quantities, requires

$$
q G^{*}=(1-\beta)\left(\alpha_{1} p x_{1}^{*}+\alpha_{2} p x_{2}^{*}\right) \quad \Longleftrightarrow \quad b=(1-\beta) A .
$$

From the right-hand expressions in (45) and (46), it is easy to derive $A=\frac{b r}{r-1}$ and $\beta=1 / r$ as claimed in (43).

The intuition behind this optimal asymmetric mechanism is as follows. In equilibrium, the contributions $\alpha_{i} p x_{i}$ which enter the lottery in (44) are endogenously equalised through the optimal choice of the individual tax rates $\alpha_{i}$, such that $\alpha_{i}^{*} p x_{i}^{*}=A$ in equilibrium. There are infinitely

\footnotetext{
${ }^{26}$ We show equilibrium existence by example in figure 3 for the two-players case. This, in turn, shows that the equilibrium set that proposition 4 is applied to is non-empty.

27 Note that this is no longer the case when preferences for the public good differ, $b_{i} \neq b_{j}$. However, in that case efficiency can still be implemented but the optimal contest is not symmetric anymore due to different marginal utilities of the public good.
} 
many pairs $\left(\alpha_{1}, \alpha_{2}\right) \in \mathbb{R}_{+}^{2}$ which equalise these contributions, but there is only a single pair which implements the efficient levels of public and private good(s) for a given lottery precision $r$.

Figure 3 illustrates equilibrium existence by plotting each player's single-peaked utility for different consumption levels, given that the other player consumes the efficient quantity for example parameters $p=1 / 10, q=1 / 20, a_{1}=6 / 10, a_{2}=3 / 10, b=1 / 10, r=2$.

The following result generalises (43) to the case of $n \geq 2$ players. We emphasise that equilibrium existence is taken as given in this proposition. It follows from the explicit example calculated in figure 3 that the set of equilibria is non-empty. A tight equilibrium existence characterisation, however, is well outside the scope and concern of the present paper. ${ }^{28}$

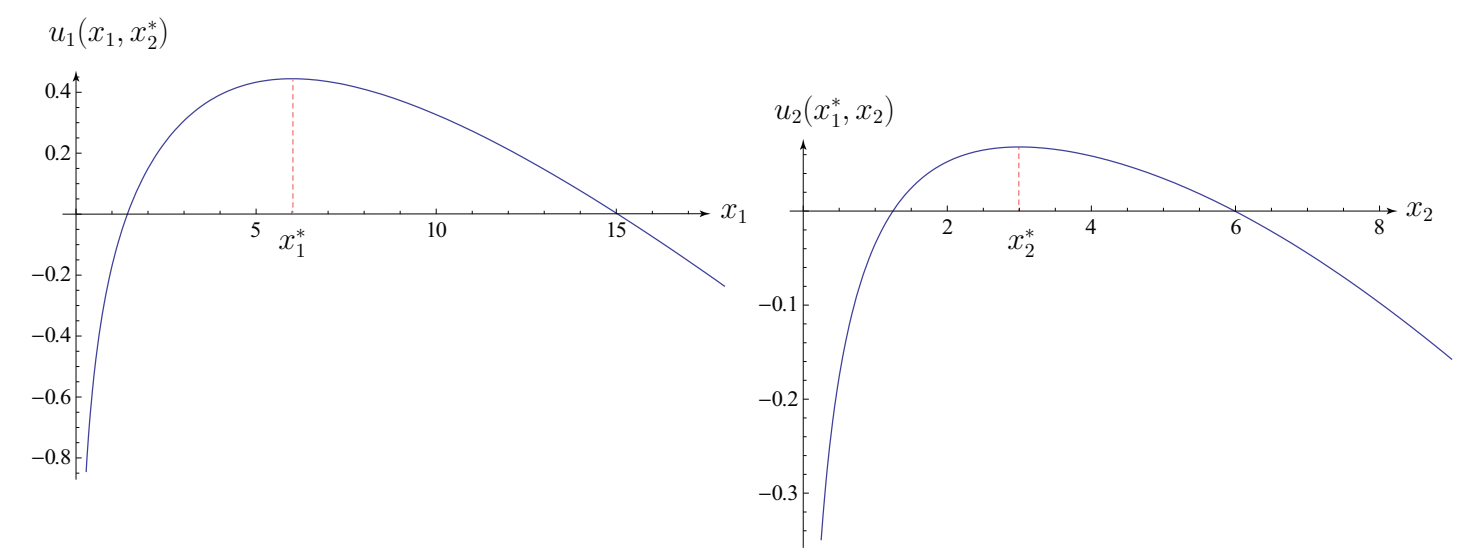

Figure 3: Players' best response problems in a two player asymmetric model (showing all maxima).

Proposition 4. For the class of asymmetric Cobb-Douglas utility functions of the form $v_{i}\left(x_{i}, G\right)=$ $a_{i} \log \left(x_{i}\right)+b \log (G)$ with $a_{i}, b>0, i \in \mathcal{N}$, the efficient allocation (42) is implemented in purestrategy Nash equilibrium through the asymmetric tax lottery mechanism

$$
\left\langle\left(\alpha_{1}^{*}, \ldots, \alpha_{n}^{*}\right), \beta^{*}, r\right\rangle=\left\langle\left(\frac{A}{a_{1}}, \ldots, \frac{A}{a_{n}}\right), \frac{1}{r}, r\right\rangle, \quad A=\frac{b r}{r-1} .
$$

Player $i$ 's optimal individual tax rate depends on the (symmetric) preferences for the public good, as well as the contest parameter $r$. As before, the parameter $r$ provides a degree of freedom to the contest designer. It is easy to see that this result coincides with that of the symmetric case in (24) for $a_{i}=a_{j}=a, j, i \in \mathcal{N}$.

Note that we assumed symmetric preferences for the public good, $b_{i}=b_{j}=b$, for presentation purposes only. Considering asymmetric preferences does not change anything in principle. In particular, the number of variables and the number of the designer's instruments are unaffected.

\footnotetext{
${ }^{28}$ We would like to point the reader to the recent Franke and Leininger (2013) who provide a complete characterisation (including existence argument) for the 'optimally levelled' Tullock contest for exponent $r=1$ in a pure fundraising game without private consumption good or tax. In our taxation setup, however, the case of $r=1$ is not capable of producing first-best and thus our analyses are complementary.
} 
However, analytical solutions are unobtainable under endogenous provision of the public good. ${ }^{29}$ Explicit solutions can be computed for specific values of the model parameters.

Since the optimal asymmetric tax lottery (47) implements first-best, it necessarily dominates the inefficient tax. The simple tax, however, has the advantage that it is anonymous, i.e., it uses only a single instrument $\alpha_{t}$ where the optimal asymmetric tax lottery requires one instrument $\alpha_{i}$ per player to implement full efficiency. We therefore continue our discussion of the asymmetric tax lottery mechanism under an anonymity assumption which restricts the government to employing only a single tax rate for all players. Hence, the following subsection incorporates private information in the sense that the government cannot distinguish between citizens.

\subsection{The anonymous mechanism}

This subsection extends our asymmetric, perfect information model into a setting where the government knows, perhaps from previous tax and consumption records, the preferences of the agents but cannot tell or verify which individual is endowed with which preferences. Because of this player anonymity, the government restricts itself to setting a single triple consisting of tax rate $\alpha$, an incentive prize share $\beta$ and the lottery precision exponent of $r$.

In this framework it is generally impossible to implement efficiency using an anonymous tax lottery. The question we therefore study below is whether or not the anonymity-constrained lottery mechanism can achieve higher welfare than a simple tax scheme in the same environment. For the purpose of answering this 'second-best' question we consider two commonly known consumer types where each type occurs $k_{1}$ and $k_{2}$ times, respectively, in the population, $k_{1}+k_{2}=n$. We assume that each player's type is private information. ${ }^{30}$ The two types differ in their preferences for the private as well as the public good. The corresponding social planner's problem is

$$
\max _{\left(x_{1}, \ldots, x_{n}, G\right)} \sum_{j=1}^{k_{1}}\left(a_{1} \log \left(x_{j}\right)+b_{1} \log (G)\right)+\sum_{j=k_{1}+1}^{n}\left(a_{2} \log \left(x_{j}\right)+b_{2} \log (G)\right)-\sum_{j=1}^{n} p x_{j}-q G,
$$

with the symmetric efficient solution

$$
x_{(1)}^{*}=\frac{a_{1}}{p}, x_{(2)}^{*}=\frac{a_{2}}{p}, G^{*}=\frac{k_{1} b_{1}+k_{2} b_{2}}{q} .
$$

Consider the anonymity-constrained tax lottery mechanism, assuming that there is a symmetric purestrategy equilibrium, where players of the same type play the same strategy. Denote the candidate equilibrium consumption quantities of the two types by $x_{(1)}$ and $x_{(2)}$. Equilibrium tax revenue is

${ }^{29}$ For the exogenous provision case, and heterogeneous preferences for the public as well as the private good $\left(u_{i}=a_{i} \log \left(x_{i}\right)+b_{i} \log (G)\right)$, the optimal efficiency-inducing mechanism is

$$
\left\langle\left(\alpha_{1}^{*}, \ldots, \alpha_{n}^{*}\right), \beta^{*}, r\right\rangle=\left\langle\left(\frac{\tilde{A}}{a_{1}}, \ldots, \frac{\tilde{A}}{a_{n}}\right), \frac{n}{r(n-1)+1}, r\right\rangle, \quad \tilde{A}=\frac{\sum_{j=1}^{n} b_{j}}{n} \frac{r(n-1)+1}{(n-1)(r-1)}
$$

\footnotetext{
${ }^{30}$ It is easy to extend this setup to a larger number of types.
} 
$P=\alpha p\left(k_{1} x_{(1)}+k_{2} x_{(2)}\right)$. Then player $i$, being of type 1 , maximises

$$
\begin{aligned}
u_{i}= & a_{1} \log x_{1}+b_{1} \log \left(\frac{(1-\beta)}{q} \alpha p\left(x_{i}+\left(k_{1}-1\right) x_{(1)}+k_{2} x_{(2)}\right)\right)-(1+\alpha) p x_{i} \\
& +\frac{x_{i}^{r}}{x_{i}^{r}+\left(k_{1}-1\right) x_{(1)}^{r}+k_{2} x_{(2)}^{r}} \beta \alpha p\left(x_{i}+\left(k_{1}-1\right) x_{(1)}+k_{2} x_{(2)}\right) .
\end{aligned}
$$

The first-order condition, evaluated at $x_{i}=x_{(1)}$ and simplified, is

$$
\begin{aligned}
& \frac{a_{1}}{x_{(1)}}+\frac{b_{1}}{k_{1} x_{(1)}+k_{2} x_{(2)}}-(1+\alpha) p \\
& \quad+\frac{r x_{(1)}^{r-1}\left(\left(k_{1}-1\right) x_{(1)}^{r}+k_{2} x_{(2)}^{r}\right)}{\left(k_{1} x_{(1)}^{r}+k_{2} x_{(2)}^{r}\right)^{2}} \beta \alpha p\left(k_{1} x_{(1)}+k_{2} x_{(2)}\right)+\frac{x_{i}^{r}}{k_{1} x_{(1)}^{r}+k_{2} x_{(2)}^{r}} \beta \alpha p=0 .
\end{aligned}
$$

Interestingly, with two types of players, the number of variables $\left(x_{(1)}, x_{(2)}, G\right)$ is equal to the number of instruments $(\alpha, \beta, r)$ (recall that in the symmetric setting, the mechanism has a degree of freedom). This implies that, in principle, there might exist an efficient tax lottery mechanism. In order to illustrate this, consider the simplest case of only two players, i.e., $k_{1}=k_{2}=1$. Then (51), evaluated at the efficient quantities (49), and simplified, becomes

$$
-\alpha+\frac{b_{1}}{a_{1}+a_{2}}+\frac{r a_{1}^{r-1} a_{2}^{r}}{\left(a_{1}^{r}+a_{2}^{r}\right)^{2}} \beta \alpha\left(a_{1}+a_{2}\right)+\frac{a_{1}^{r}}{a_{1}^{r}+a_{2}^{r}} \beta \alpha=0 .
$$

The corresponding condition for a type-2 player is

$$
-\alpha+\frac{b_{2}}{a_{1}+a_{2}}+\frac{r a_{2}^{r-1} a_{1}^{r}}{\left(a_{1}^{r}+a_{2}^{r}\right)^{2}} \beta \alpha\left(a_{1}+a_{2}\right)+\frac{a_{2}^{r}}{a_{1}^{r}+a_{2}^{r}} \beta \alpha=0 .
$$

Budget balance, $q G=(1-\beta) \alpha p\left(k_{1} x_{(1)}+k_{2} x_{(2)}\right)$, evaluated at the efficient quantities (49) delivers

$$
(1-\beta) \alpha=\frac{b_{1}+b_{2}}{a_{1}+a_{2}}
$$

Every solution of the simultaneous equation system (52)-(54) is an efficient candidate equilibrium. For example, the numerically derived mechanism parameterised by

$$
\left\langle\alpha^{*}=0.0377681467261600, \beta^{*}=0.0468158191340469, r^{*}=3.46913491948015\right\rangle
$$

exactly implements an efficient equilibrium for the parameter values $a_{1}=1 / 2, a_{2}=1 / 3, b_{1}=1 / 100$, $b_{2}=1 / 50, p=q=1 / 100$ as verified by figure 4 .

The intuition why we can achieve full efficiency in a two-type model with private information rests on two observations: First, the tax lottery mechanism is anonymous, in the sense that it applies to all players in the same way. Only the total number of players of each type plays a role, rather than their identities. But these parameters are common knowledge. The same is true for each player's best response problem and the welfare maximisation problem. Thus, the mechanism can employ the same information as the first-best benchmark. Second, recall that the optimal mechanism in the fully 

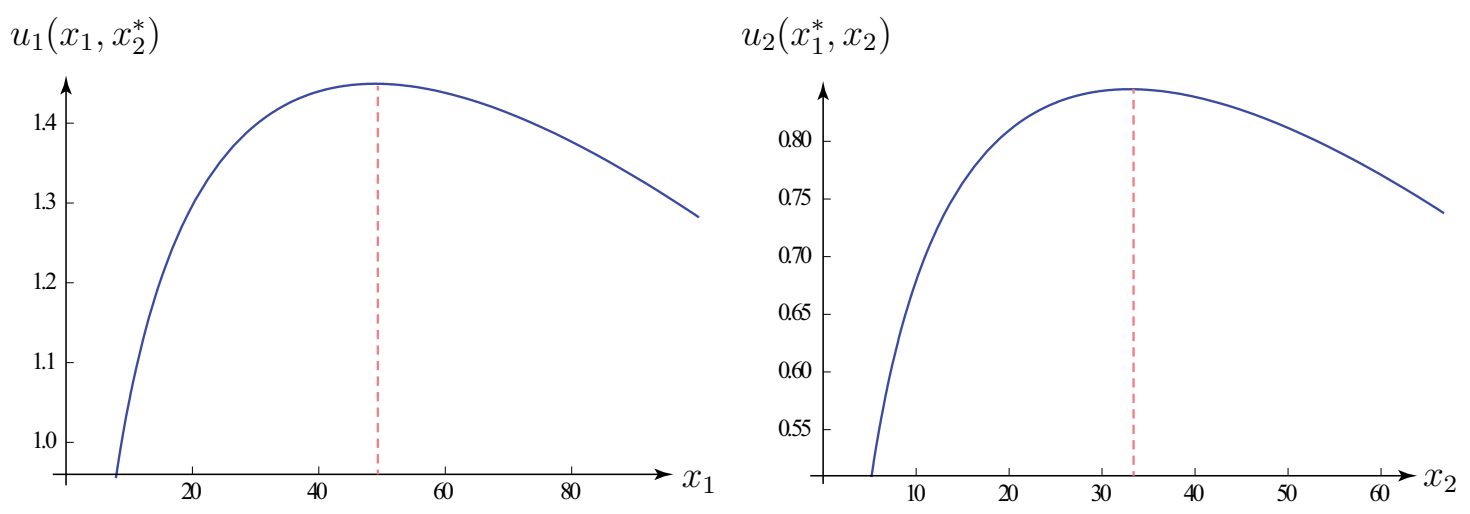

Figure 4: Players' best response problems in a two player asymmetric and anonymous model.

symmetric model has a degree of freedom. There, we had infinitely many optimal mechanisms, e.g., we expressed the optimal $\alpha$ and $\beta$ as functions of an arbitrarily chosen $r$. Now, in the anonymous mechanism, manipulating the remaining parameter (say, $r$ ), allows us to fine-tune the difference in the equilibrium private consumption levels $x_{(1)}$ and $x_{(2)}$, whereas this difference was zero in the complete information model.

Note that the simple sales tax mechanism is a special case of our mechanism, obtained by removing the lottery through setting $\beta=0$. Thus, for comparison, the welfare maximising simple sales tax mechanism is obtained by setting $\beta=0$ in (50) and (51). It can be seen that, in this case, the equilibrium quantities $x_{(1)}$ and $x_{(2)}$ in (51) can be determined analytically. Inserting them into (48), and replacing $G$ by the budget-balancing amount $\alpha p\left(k_{1} x_{(1)}+k_{2} x_{(2)}\right) / q$ delivers the corresponding welfare function. Maximising over tax rates $\alpha$, the optimal tax rate is

$$
\alpha_{t}=\frac{k_{1} b_{1}+k_{2} b_{2}}{k_{1} a_{1}+k_{2} a_{2}}
$$

In order to evaluate the performance of the anonymous tax lottery in terms of welfare, we illustrate numerical results for three two-type populations with one, two and three consumers of each type, respectively, i.e., $k_{1}=k_{2}=k$ with $k \in\{1,2,3\}$.

The below figure 5 compares the numerically approximated "second-best" welfare achieved by the tax lottery, $W^{\text {sb }}$, with the analytically derived first-best welfare $W^{*}$ and the welfare achieved by the optimal simple sales tax $W^{t}$. In the figure, the first-best welfare is normalised to one and the welfare of the simple tax is normalised to zero. Thus, we plot the mechanism's performance relative to first-best and the simple tax. We illustrate the role of asymmetry by plotting the ratio $a_{1} / a_{2}$ on the abscissa, from close to zero to the symmetric case $a_{1} / a_{2}=1$. There, the tax lottery is exactly first-best, corresponding to our results for the symmetric case. The parameters used for the plot are $a_{1}=\{0.05,0.10, \ldots, 0.95\}, a_{2}=0.95, p=q=.01, b_{1}=b_{2}=.2$; the interpolation between data points is quadratic. ${ }^{31}$ Since the precise relationships are hard to express in a single figure, we present the tabulated numerical results in the appendix. Note that the plot only provides a lower bound on the mechanism's performance, due to the numerical methods used (while the benchmark

31 We confirmed equilibrium existence of the anonymity constrained, asymmetric tax lottery mechanism for each of the 19 individual data points for all three economies in figure 5. 
values for first-best and simple tax are computed analytically).

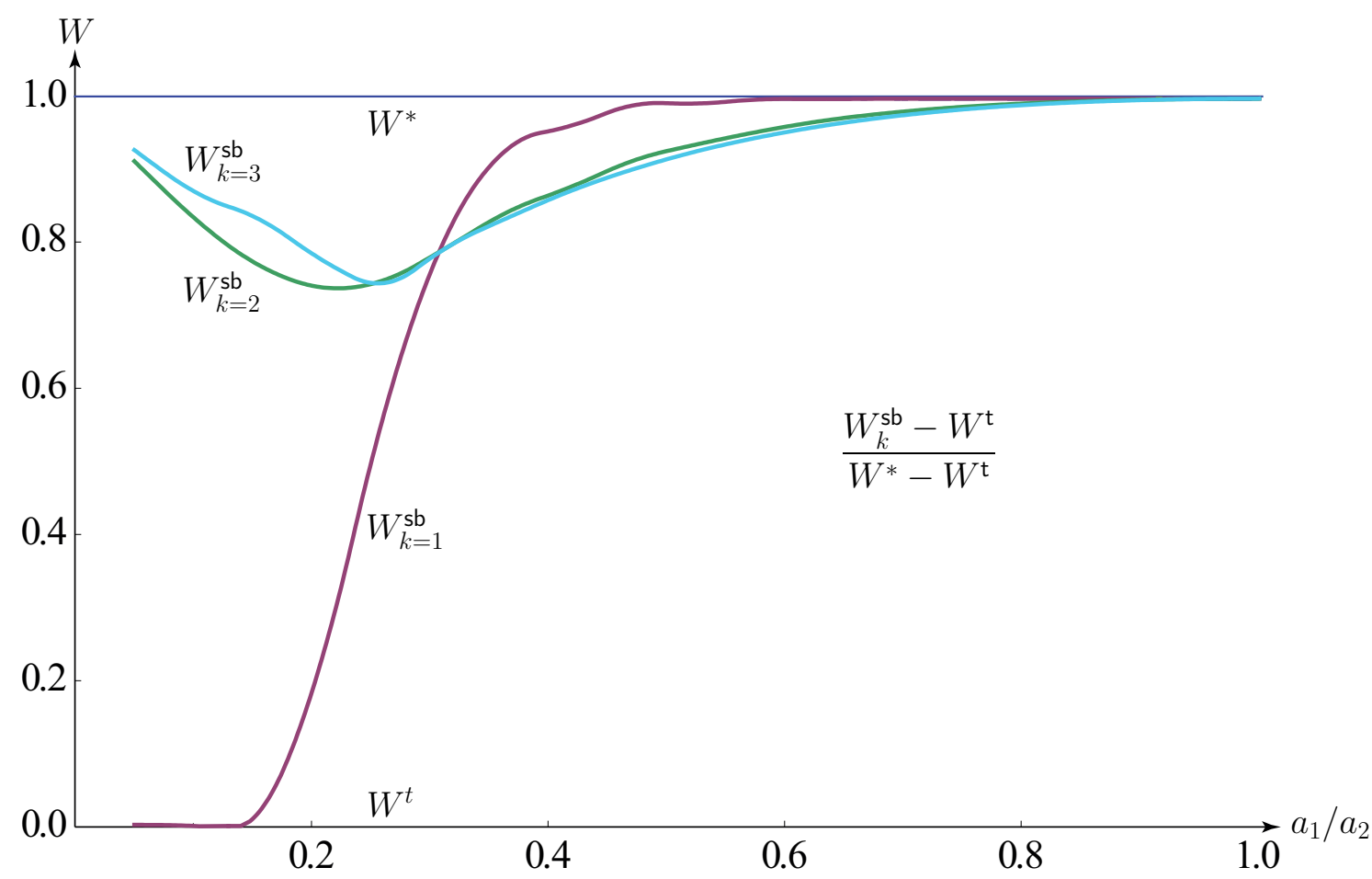

Figure 5: Welfare comparison between the efficient mechanism $W^{*}$ (blue, normalised to one), the tax lottery (purple $k=1$, green $k=2$, light blue $k=3$ ), and a simple tax $W^{t}$ (abscissa, normalised to zero).

We have chosen very low values of $k$, i.e., very small economies, in order to better illustrate the size effect on the mechanism's performance. The case $k=1$ represents the 'worst case' in the sense that with only two asymmetric players, it is hard to give incentives through a lottery (as can be seen for low values of $a_{1} / a_{2}$ where the tax lottery does not perform better than a simple sales tax). This is because the player who values the private good a lot wins the lottery almost with certainty, removing the other player's incentives to consume more than without a lottery. As a consequence, both players have no incentives to 'invest' in additional consumption. This result changes with larger $k$, because then there is 'intra-group' competition within the group of consumers belonging to the same type. This effect is strong and is already substantial when moving from one to two players in each type-group (the case $k=2$ ). Thus, in large economies, the presence of many symmetric players in each group induces strong incentives through the lottery mechanism, improving welfare. This effect should continue to hold if there are more types of consumers in the economy, implying that the anonymous tax lottery can generate substantially higher welfare than the simple tax mechanism.

\subsection{A larger number of goods}

The following example illustrates that the proposed tax lottery scheme continues to work for a larger number of goods. Consider a symmetric model with two private goods (with prices $p_{1}$ and $p_{2}$ ) and two public goods (produced according to cost functions $C_{1}\left(G_{1}\right)=q_{1} G_{1}$ and $C_{2}\left(G_{2}\right)=q_{2} G_{2}$ ). 
Assume that $v\left(x_{1}, x_{2}, G_{1}, G_{2}\right)=x_{1}^{a_{1}} x_{2}^{a_{2}} G_{1}^{b_{1}} G_{2}^{b_{2}}$ with $a_{1}, a_{2}, b_{1}, b_{2} \in(0,1)$ and $a_{1}+a_{2}+b_{1}+b_{2}<1$. The social planner's (symmetric) problem is then to

$$
\max _{x_{1}, x_{2}, G_{1}, G_{2}} n\left(w+x_{1}^{a_{1}} x_{2}^{a_{2}} G_{1}^{b_{1}} G_{2}^{b_{2}}-p_{1} x_{1}-p_{2} x_{2}\right)-q_{1} G_{1}-q_{2} G_{2}
$$

Using the notation $S=1-a_{1}-a_{2}-b_{1}-b_{2}$, the efficient quantities are

$$
\begin{aligned}
& x_{1}^{*}=n^{\frac{b_{1}+b_{2}}{S}}\left(\frac{a_{1}}{p_{1}}\right)^{\frac{S+a_{1}}{S}}\left(\frac{a_{2}}{p_{2}}\right)^{\frac{a_{2}}{S}}\left(\frac{b_{1}}{q_{1}}\right)^{\frac{b_{1}}{S}}\left(\frac{b_{2}}{q_{2}}\right)^{\frac{b_{2}}{S}}, \\
& x_{2}^{*}=n^{\frac{b_{1}+b_{2}}{S}}\left(\frac{a_{1}}{p_{1}}\right)^{\frac{a_{1}}{S}}\left(\frac{a_{2}}{p_{2}}\right)^{\frac{S+a_{2}}{S}}\left(\frac{b_{1}}{q_{1}}\right)^{\frac{b_{1}}{S}}\left(\frac{b_{2}}{q_{2}}\right)^{\frac{b_{2}}{S}}, \\
& G_{1}^{*}=n^{\frac{S+b_{1}+b_{2}}{S}}\left(\frac{a_{1}}{p_{1}}\right)^{\frac{a_{1}}{S}}\left(\frac{a_{2}}{p_{2}}\right)^{\frac{a_{2}}{S}}\left(\frac{b_{1}}{q_{1}}\right)^{\frac{S+b_{1}}{S}}\left(\frac{b_{2}}{q_{2}}\right)^{\frac{b_{2}}{S}}, \\
& G_{2}^{*}=n^{\frac{S+b_{1}+b_{2}}{S}}\left(\frac{a_{1}}{p_{1}}\right)^{\frac{a_{1}}{S}}\left(\frac{a_{2}}{p_{2}}\right)^{\frac{a_{2}}{S}}\left(\frac{b_{1}}{q_{1}}\right)^{\frac{b_{1}}{S}}\left(\frac{b_{2}}{q_{2}}\right)^{\frac{S+b_{2}}{S}} .
\end{aligned}
$$

Under the tax lottery scheme, the respective private goods are taxed with tax rates $\alpha_{1}$ and $\alpha_{2}$. As before, the revenue pool $P$ equals total tax revenues. The shares $\gamma_{1}$ and $\gamma_{2}$ of the revenue pool are used to finance the two public goods, respectively. The remaining share, $1-\gamma_{1}-\gamma_{2}$ is paid to the contest winner. Each player's total consumption enters the contest. Assuming that the other players play the symmetric strategies $x_{1 j}>0$ and $x_{2 j}>0$, player $i$ maximises

$$
\begin{aligned}
u_{i}\left(x_{1 i}, x_{2 i}\right)= & w+x_{1 i}^{a_{1}} x_{2 i}^{a_{2}} G_{1}^{b_{1}} G_{2}^{b_{2}}-\left(1+\alpha_{1}\right) p_{1} x_{1 i}-\left(1+\alpha_{2}\right) p_{2} x_{2 i} \\
& +\frac{\left(x_{1 i}+x_{2 i}\right)^{r}}{\left(x_{1 i}+x_{2 i}\right)^{r}+(n-1)\left(x_{1 j}+x_{2 j}\right)^{r}}\left(1-\gamma_{1}-\gamma_{2}\right) P \\
\text { s.t. } & q_{1} G_{1}=\gamma_{1} P, q_{2} G_{2}=\gamma_{2} P \\
\text { and } \quad & P=\alpha_{1} p_{1}\left(x_{1 i}+(n-1) x_{1 j}\right)+\alpha_{2} p_{2}\left(x_{2 i}+(n-1) x_{2 j}\right) .
\end{aligned}
$$

Using steps similar to those in the subsection 3.1, we find the following optimal scheme

$$
\begin{aligned}
\alpha_{1}^{*} & =\frac{r}{r-1} \frac{\left(b_{1}+b_{2}\right) p_{2}}{a_{1} p_{2}+a_{2} p_{1}}, \quad \alpha_{2}^{*}=\frac{r}{r-1} \frac{\left(b_{1}+b_{2}\right) p_{1}}{a_{1} p_{2}+a_{2} p_{1}} \\
\gamma_{1}^{*} & =\frac{r-1}{r} \frac{b_{1}}{b_{1}+b_{2}}, \quad \gamma_{2}^{*}=\frac{r-1}{r} \frac{b_{2}}{b_{1}+b_{2}} .
\end{aligned}
$$

Checking the example $\left(a_{1}, a_{2}, b_{1}, b_{2}, p_{1}, p_{2}, q_{1}, q_{2}, n, r\right)=(1 / 8,1 / 8,1 / 100,1 / 100,1,1,1,1,10,3)$ ensures that the set of equilibria for this scheme is non-empty and open.

\subsection{Generalised ranking technologies}

In order to simplify the exposition in the main part of the paper we employ there the widely used Tullock contest success function to determine winning probabilities. This, of course, is only one of many possible contest or lottery specifications. In the following we demonstrate our main results for a more general form of noisy consumption ranking. ${ }^{32}$ Let us now assume that there exists a noisy

\footnotetext{
32 The general idea of our specification follows Gershkov, Li, and Schweinzer (2009), adapted to the present setup.
} 
and partial but verifiable ranking of private good consumption decisions

$$
\Gamma(\tilde{\mathbf{x}})=\left[\pi_{1}\left(\tilde{x}_{1}\right), \ldots, \pi_{n}\left(\tilde{x}_{n}\right)\right]
$$

where $x_{i j}=x_{i} / x_{j}$ and $\tilde{x}_{i}=\left(x_{i 1}, x_{i 2}, \ldots, x_{i n}\right)$, where the $i^{t h}$ element is 1 . Thus (61) ranks the players on the basis of ratios between consumption pairs such that $\pi_{i}\left(\tilde{x}_{i}\right)$ is player $i$ 's probability of being ranked first given the consumption vector $\mathbf{x}=\left(x_{1}, \ldots, x_{n}\right)$. We make the following assumptions on $\pi_{i}(\cdot)$ :

A1 Symmetry: For any two players $l \neq m$ and for any two consumption vectors, $\left(x_{1}, \ldots, x_{n}\right)$ and $\left(x_{1}^{\prime}, \ldots, x_{n}^{\prime}\right)$ with $x_{k}=x_{k}^{\prime}$ for $k \notin\{l, m\}$ and $x_{l}=x_{m}^{\prime}$ and $x_{m}=x_{l}^{\prime}$, we have $\pi_{l}\left(\tilde{x}_{l}\right)=$ $\pi_{m}\left(\tilde{x}_{m}^{\prime}\right)$. Moreover, for any player $i$, let the elements of a consumption ratio vector $\tilde{x}_{i}^{\prime}$ be arbitrary permutations of those in $\tilde{x}_{i}$ except for the element at the $i$ th position. For these we require that $\pi_{i}\left(\tilde{x}_{i}\right)=\pi_{i}\left(\tilde{x}_{i}^{\prime}\right)$.

A2 Responsiveness: For any $l \in\{1, \ldots, n\}$ and $l \neq i, \frac{\partial \pi_{i}\left(\tilde{x}_{i}\right)}{\partial x_{i l}}>0$.

A3 $\pi(\cdot)$ is twice continuously differentiable.

A1 says that every opponent of player $i$ affects the winning probability of $i$ in a similar way. Thus, if players $l$ and $m$ exchange their consumption levels, this does not affect the winning probability of player $i \notin\{l, m\}$. The interpretation of $\mathbf{A} 2$ is that the probability of being ranked first should react positively to increased consumption. A3 is technical (and excludes the case of the all-pay auction). A1 also implies that in symmetric equilibrium, where $x_{1}=\cdots=x_{n}$, the slope of $\pi_{i}$ with respect to any ratio $x_{i j}$ is the same for all $i, j \in \mathcal{N}$, and each ratio is equal to 1 . We simply denote this slope by $\pi^{\prime}(1)$.

This class of contests includes the generalised Tullock success function used in the main body of the paper, since

$$
\pi_{i}\left(\tilde{x}_{i}\right)=\left(\sum_{j=1}^{n} x_{i j}^{-r}\right)^{-1}=\frac{x_{i}^{r}}{\sum_{j=1}^{n} x_{j}^{r}}, \quad r>0 .
$$

Therefore, we already know that the class of efficient equilibria is not empty. Similarly to our base model, player $i$ 's utility is

$$
\begin{aligned}
& u_{i}=w+v\left(x_{i}, G\right)-(1+\alpha) p x_{i}+\pi_{i}\left(\tilde{x}_{i}\right) \beta P \\
& \text { s.t. } C(G)=(1-\beta) P \text {, and } P=\alpha p\left(x_{i}+(n-1) x_{j}\right) .
\end{aligned}
$$

Based on this model, we can characterise the optimal tax lottery scheme as follows

Proposition 5. If $n \geq 2$ and $\pi^{\prime}(1)>1 / 4$, there is an efficient tax lottery scheme characterised by

$$
\beta^{*}=\frac{1}{n^{2} \pi^{\prime}(1)} \quad \text { and } \quad \alpha^{*}=\frac{C\left(G^{*}\right) / n}{p x^{*}} \frac{1}{1-\beta^{*}} .
$$

Using (62), it is easily verified that this corresponds to our results for the Tullock-Cobb-Douglas example where $\pi^{\prime}(1)=r / n^{2}$. 
Finally, note that no ratio based probabilistic or shares-based assignment can work for infinite populations where winning probabilities or shares (62) must necessarily be zero. The model works without any problems, however, for arbitrary large but finite numbers of players.

\subsubsection{Contests with difference-based ranking}

In this last robustness check, we present a simple two-players version of the example of section 3.1 based on the difference form success function introduced by Hirshleifer (1989). ${ }^{33}$ The social planner's problem is unchanged and thus the efficient quantities $x^{*}$ and $G^{*}$ are still given by (19). Using a tax lottery scheme, player $i$ 's utility is now

$$
\begin{gathered}
u_{i}=w+x_{i}^{a} G^{b}+\frac{1}{1+\exp \left(r\left(x_{j}-x_{i}\right)\right)} \beta P-(1+\alpha) p x_{i} \\
\text { s.t. } q G=(1-\beta) P, \text { and } P=\alpha p\left(x_{i}+x_{j}\right)
\end{gathered}
$$

where $r>0$ can be interpreted in a way similar to the Tullock model. Working through steps identical to those outlined in the example section and setting $x=x^{*}$ for $n=2$ from (19), we obtain the same optimality condition (23) as in the example section. For the difference-form contest success function, the efficiency inducing parameters are

$$
\beta^{*}=\frac{1}{r x^{*}}, \alpha^{*}=\frac{b}{a} \frac{r x^{*}}{r x^{*}-1} .
$$

Existence can be confirmed by a graph which is almost identical to figure 1 for the same parametrisation as stated in footnote 23 .

\section{Concluding remarks}

This paper is motivated by theoretical interest in sales taxation and existing tax receipt lottery schemes in place, for instance, in Taiwan, mainland China, and Puerto Rico. These schemes combine a sales tax with a lottery and have been highly successful in their intended purpose of reducing tax evasion. Our paper shows that, in addition, the same set of tools makes efficiency results possible which we present in the classical setting of public goods provision using sales taxes. Starting from Samuelson's well-known inefficiency result, we show that siphoning off a share of tax revenue into an appropriately designed lottery (contest) can implement efficiency, i.e., induce undistorted private consumption and finance the public good at the efficient level.

In an environment where private and public goods consumption is nonseparable, simple lotteries as well as (generalised) pure fundraising contests fail to achieve efficiency. Incorporating private consumption into the model seems important because, in the absence of a private good, efficiency is defined in the public good dimension only, where only the total sum of marginal contributions

\footnotetext{
33 This type of difference-form success function can be extended to $n>2$ players but then-depending on the precise formulation used-the difference to the ratio-form may become blurred. Hence we use the most distant 2-players case from our specification in section 3.1 for the present robustness argument.
} 
is pinned down (the Samuelson condition). With a private good and nonseparable utility, however, efficiency has another dimension, and require in addition uniquely determined individual contributions levels to the public good because changing an individual's public good contribution marginally affects the private consumption decision. This makes it harder to achieve overall efficiency. Thus, we provide a justification for the above-mentioned tax receipt lotteries in showing that both ingredients are crucial for efficiency: the sales tax and an appropriately designed contest. This paper does not discuss optimal taxation. We demonstrate that, in principle, two traditional fundraising mechanisms-sales taxes and lotteries - can be combined in order to improve the provision of public goods. Given that sales tax mechanisms are in place in many economies, our results are practically relevant in the sense that adding a lottery on top of an existing tax might lead to welfare improvements, in a way that is easy to sell to politicians' constituencies. In one of our model extensions, we argue that an anonymous tax lottery should substantially outperform a sales tax mechanism even in the presence of private information.

Throughout the paper we look at two ways of providing the public good: exogenously and endogenously, as a function of tax revenue. We do this in order to evaluate whether our efficiency result requires linking individuals' consumption decisions to the provision level of the public good. One might argue that the effect of this strategic connection is doubtful in practice. There is, however, empirical evidence that this link indeed positively affects participants' willingness to invest in a lottery. ${ }^{34}$ Our main efficiency result is obtained under both specifications for symmetric and asymmetric players.

As compared to the 'exogenous' scheme, the scheme with endogenous provision of the public good has the following characteristics. First, rational players take into account their decisions' effects on the public good. Therefore, second, there is a free-rider effect, since each player's (additional) consumption benefits everyone in terms of an increased amount of the public good. Third, given the positive link between a player's own private consumption and the public good, private consumption has an additional private benefit. Thus, a player needs less incentive through the tax lottery scheme than under exogenous provision. Indeed, we show that a given lottery can implement efficiency at a lower sales tax rate, while needing less revenue for the lottery prize (in relative and absolute terms). Fourth, if the designer is uncertain about the preferences for the public good, then the endogenous scheme provides a corrective: participants, through their consumption, 'produce' less of the public good if it is less valuable to them.

We argue that, in contrast to alternative schemes, the tax lottery scheme can achieve efficiency because, one the one hand, a generalised lottery allows the designer to fine-tune the marginal consumption decision, and, one the other hand, the lottery is run on private consumption rather than voluntary contributions. This has the advantage, that in order to 'game' the lottery or freeride on others' actions, a player has to distort his consumption, and thus its utility and cost. This provides a corrective that is not present under voluntary contribution schemes. This intuition seems to correspond to reality, where, under the existing tax receipt lotteries, it is unlikely that one would choose extreme consumption decisions just in order to exploit the tax receipt lottery. This is precisely

\footnotetext{
34 See, e.g., the subsection "Linking lotteries and public goods" in Morgan (2000).
} 
because those schemes are (and should be) relatively unimportant in comparison to the consumption decision itself. In practice, we are confident that an implementation of the lotteries designed in this paper should no be too hard: mechanisms featuring elements similar to ours have been in use for a long time.

\section{Appendix}

Proof of proposition 1. The proof proceeds by showing that in any efficient symmetric candidate equilibrium, any player $i$ has an incentive to deviate to a contribution of zero, $g_{i}=0$. (It is easy to see that smaller deviations are profitable, too.)

First, in any efficient symmetric equilibrium, with optimal lottery scheme $\gamma^{*}$, every player consumes $x^{*}$ of the private good and makes a contribution of $g^{*}$ such that the government budget is balanced when the public good is provided efficiently,

$$
C\left(G^{*}\right)=\left(1-\gamma^{*}\right) n g^{*} \quad \Longleftrightarrow \quad g^{*}=\frac{C\left(G^{*}\right)}{\left(1-\gamma^{*}\right) n} .
$$

Since all players make the same contribution, the equilibrium probability of winning a generalised lottery is $1 / n$ (see our most general lottery specification in section 5.4), and, using (67), equilibrium utility would simplify to

$$
\begin{aligned}
u_{i} & =w+v\left(x^{*}, G^{*}\right)-p x^{*}-g^{*}+\frac{1}{n} \gamma^{*} n g^{*} \\
& =w+v\left(x^{*}, G^{*}\right)-p x^{*}-\frac{C\left(G^{*}\right)}{n} .
\end{aligned}
$$

Second, after any deviation to a different contribution, $i$ 's optimal private consumption level $x_{i}$ would change as well. Throughout this proof, we ignore this and leave the consumption level at $x_{i}=x^{*}$ since, obviously, changing consumption to the new optimal level makes any deviation even more profitable.

Third, consider a deviation by player $i$ from contribution $g^{*}$ to 0 . The following argument is illustrated in figure $6 .^{35}$ If $i$ deviates to a contribution of zero, then he saves an amount of $C\left(G^{*}\right) / n$, by (68) ('deviation gain' in figure 6). This implies that total contributions are reduced to $C\left(G^{*}\right)(n-1) / n$. Denote the corresponding public goods level by $G=G^{\text {dev }}$, i.e., $C\left(G^{\text {dev }}\right)=$ $C\left(G^{*}\right)(n-1) / n$. Player $i$ 's utility from the public good changes from $v\left(x^{*}, G^{*}\right)$ to $v\left(x^{*}, G^{d e v}\right)$ ('deviation loss' in figure 6). In the efficient candidate, the slope of the utility function is below that of the cost function (by (3), the Samuelson condition). Thus, the absolute cost saving is larger than the utility loss, making the deviation profitable.

Proof of proposition 2. Throughout this proof we ignore the individual wealth level, $w$, since its only effect on the analysis is to increase each utility level by the same constant. Supposing that a symmetric equilibrium with individual consumption equal to $x$ exists, $i$ 's strategies can be represented

\footnotetext{
35 Figure 6 is plotted for linear cost. This is the worst case; the argument becomes stronger if cost is convex.
} 


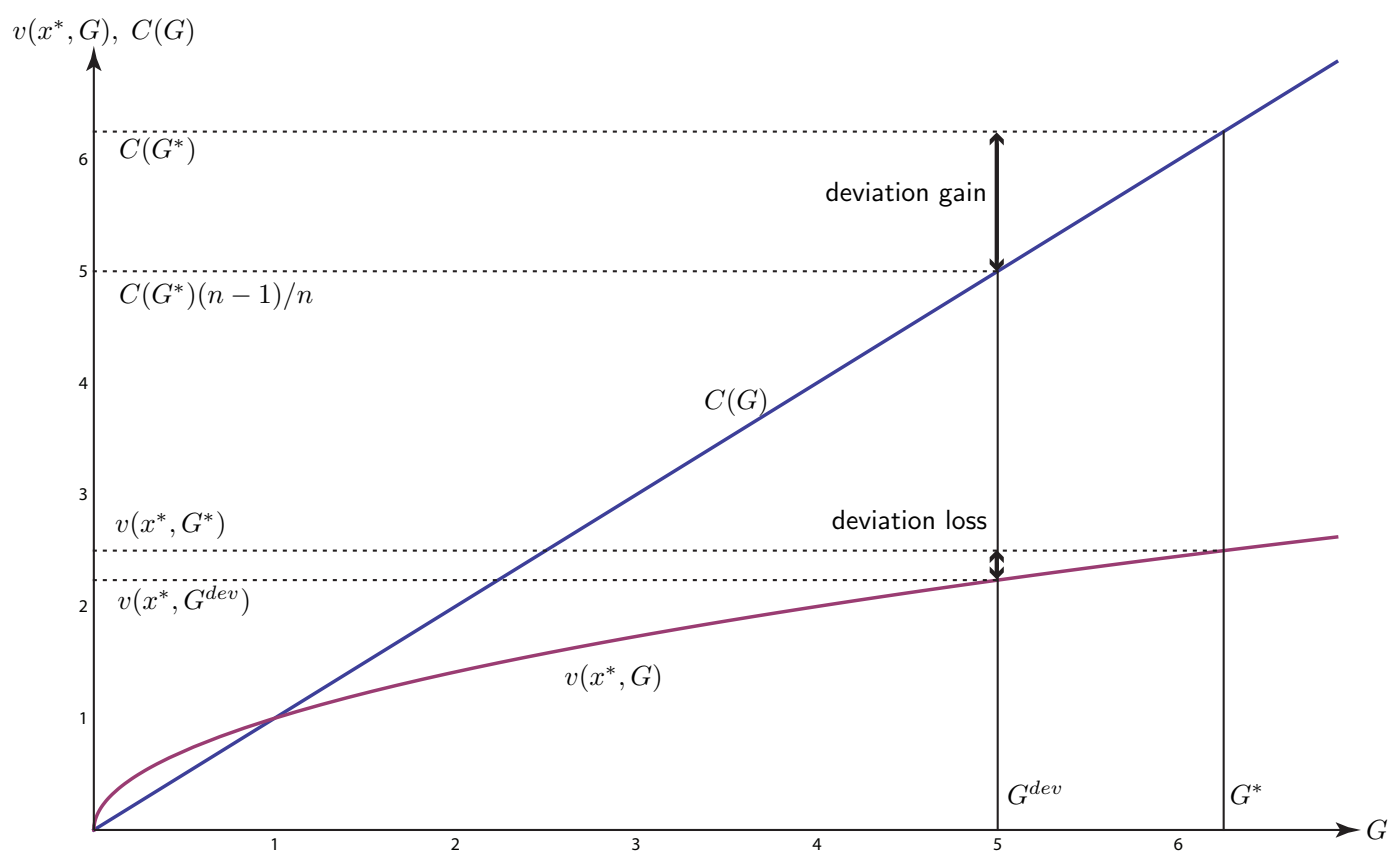

Figure 6: Deviation incentive in the efficient equilibrium candidate with contributions.

by $x_{i}=k x, k \geq 0$ with $k=1$ in the equilibrium candidate. Then player $i$ 's maximises

$$
\max _{k \geq 0} u_{i}(k)=(k x)^{a} G^{b}+\frac{(k x)^{r}}{(k x)^{r}+(n-1) x^{r}} \beta P-(1+\alpha) p(k x),
$$

where $P=\alpha p((k x)+(n-1) x)$. After inserting $P$ this can be simplified to

$$
u_{i}(k)=k^{a} x^{a} G^{b}+\frac{k^{r}}{k^{r}+n-1} \alpha \beta p(k+n-1) x-(1+\alpha) p k x .
$$

The second derivative of $u_{i}$ with respect to $k$ is

$$
u_{i}^{\prime \prime}(k)=a(a-1) k^{a-2} x^{a} G^{b}+\frac{n-1}{\left(k^{r}+n-1\right)^{2}} \alpha \beta p x r k^{r-2} \underbrace{\left(2 k+(k+n-1)(r-1)-\frac{(k+n-1) 2 r k^{r}}{k^{r}+n-1}\right)}_{=: A} .
$$

After inserting $x^{*}, G^{*}, \alpha^{*}$, and $\beta^{*}$ (derived in (19) and (22)), using $A$ defined in the line above, and simplifying, this can be written as

$$
u_{i}^{\prime \prime}(k)=\left(\frac{a}{p}\right)^{\frac{a}{1-a-b}}\left(\frac{b n}{q}\right)^{\frac{b}{1-a-b}}(\underbrace{a(a-1) k^{a-2}}_{=: B<0}+\frac{b n r k^{r-2}}{\left(k^{r}+n-1\right)^{2}(r-1)} A) .
$$

For the sign of $u_{i}^{\prime \prime}(k)$ above, only the big parenthesis is relevant (the factor in front of it is positive). Since $0<a<1$, the term $B$ is negative. The parameter $b$ occurs only once in the big parenthesis, as a factor. Clearly, for any given $k>0$ there is a sufficiently small $b$ such that the first (negative) term outweighs the second term, making the whole parenthesis negative, for given values of all other parameters. Thus, $u_{i}^{\prime \prime}(k)<0$, ensuring a strictly concave utility, for $k>0$. Utility in the equilibrium 
candidate, $k=1$, can be computed to be positive:

$$
u_{i}(k=1)=(1-a-b)\left(\frac{a}{p}\right)^{\frac{a}{1-a-b}}\left(\frac{b n}{q}\right)^{\frac{b}{1-a-b}} .
$$

Thus, the first-order condition (where $k=1$ ) is sufficient for a global utility maximum.

The 'critical' value of $b$ (below which existence is ensured) is the largest value of $b$ such that the big parenthesis in (72) is nonpositive for every $k>0$ (we have ruled out that $k=0$ is optimal). In order to compute this 'critical' $b$, one maximises the parenthesis with respect to $k$, replacing $k$ by the maximiser $k^{*}$, i.e., $i$ 's most profitable deviation. Then one solves for the value of $b$ such that the parenthesis has a value of zero.

Proof of proposition 3. Throughout this proof we ignore the individual wealth level, $w$, since its only effect on the analysis is to increase each utility level by the same constant. Supposing that a symmetric equilibrium with individual consumption equal to $x$ exists, $i$ 's strategies can be represented by $x_{i}=k x, k \geq 0$ (with $k=1$ in the equilibrium candidate) while the other players play $x$. Then $i$ maximises

$$
u_{i}(k)=k^{a}\left(\frac{(1-\beta) p \alpha(k+n-1)}{q}\right)^{b} x^{a+b}-p x\left((1+\alpha) k-k^{r} \frac{k+n-1}{k^{r}+n-1} \alpha \beta\right) .
$$

Replacing $\alpha$ and $\beta$ with the optimal levels given in (24) yields

$$
u_{i}(k)=k^{a}\left(\frac{b p(k+n-1)}{a q}\right)^{b} x^{a+b}-p x\left(k+\frac{b}{a(r-1)}\left(k r-k^{r} \frac{k+n-1}{k^{r}+n-1}\right)\right) .
$$

Setting $x=x^{*}$ from (19) gives

$$
\begin{gathered}
u_{i}(k)=\underbrace{\left(\frac{a}{p}\right)^{\frac{a}{1-a-b}}\left(\frac{b n}{q}\right)^{\frac{b}{1-a-b}}}_{=: D} \\
\left(k(1-a-b)-\frac{b}{r-1}\left(k-\frac{k^{r}(k-1+n)}{\left(k^{r}-1+n\right)}\right)-k+k^{a}\left(\frac{k-1+n}{n}\right)^{b}\right) .
\end{gathered}
$$

Compute the second derivative of $u_{i}(k)$,

$$
\begin{aligned}
u_{i}^{\prime \prime}(k)= & D\left(\frac{k+n-1}{n}\right)^{b}\left(b k^{r-2} r(n-1) n^{b} \frac{\left((r-1)(n-1)-k^{r}(r+1)\right)(k+n-1)+2 k\left(k^{r}+n-1\right)}{(k+n-1)^{b}\left(k^{r}+n-1\right)^{3}(r-1)}\right. \\
& \left.+b \frac{k^{a-1}}{(k+n-1)^{2}}((b-1) k+2 a(k+n-1))+a(a-1) k^{a-2}\right)
\end{aligned}
$$

The sign of (77) depends on the large parenthesis (since $D\left(\frac{k+n-1}{n}\right)^{b}$ is positive). Inside, the last term, $a(a-1) k^{a-2}$ is independent of $b$ and strictly negative. The other two terms contain $b$ as a factor. If we reduce $b$, then this last term will at some point "outweigh" the other terms in the parenthesis, making the whole expression negative, for any given $k>0$. Moreover, utility in the 
equilibrium candidate, $k=1$, can be computed to be positive, ruling out that $k=0$ can be optimal.

$$
u_{i}(k=1)=(1-a-b)\left(\frac{a}{p}\right)^{\frac{a}{1-a-b}}\left(\frac{b n}{q}\right)^{\frac{b}{1-a-b}}
$$

Thus, $u_{i}(k)$ becomes strictly concave in $k$ and the first-order condition, where $k=1$, becomes sufficient. In order to compute the 'critical' $b$ below which existence is ensured, one maximises the big parenthesis in (77) with respect to $k$, replacing $k$ by the maximiser $k^{*}$, i.e., $i$ 's most profitable deviation. Then one solves for the value of $b$ such that the parenthesis has a value of zero.

Proof of proposition 5. The proof proceeds as follows. We suppose that a symmetric efficient equilibrium exists, characterised by the first-order condition of player $i$ 's best-reply problem, where the other players $j \neq i$ play $x_{j}=x^{*}$. First, we derive $\beta^{*}$. Second, we derive the equilibrium tax rate, $\alpha^{*}$. Third, we derive conditions ensuring feasibility of the equilibrium parameters $\alpha^{*}, \beta^{*}$, and $P$.

1) Suppose that a symmetric equilibrium $x_{j}>0$ exists. Then $x_{i k}=x_{i l}=\frac{x_{i}}{x_{j}}$ for all $k, l \in \mathcal{N} \backslash i$. Thus, $\pi_{i}\left(\tilde{x}_{i}\right)=\pi_{i}\left(\frac{x_{i}}{x_{j}}, \ldots, 1, \ldots, \frac{x_{i}}{x_{j}}\right)$, with " 1 " at the $i$ 'th position. Then $i$ 's utility is

$$
u_{i}=w+v\left(x_{i}, G\right)-(1+\alpha) p x_{i}+\pi_{i}\left(\frac{x_{i}}{x_{j}}, \ldots, 1, \ldots, \frac{x_{i}}{x_{j}}\right) \beta \alpha p\left(x_{i}+(n-1) x_{j}\right),
$$

Since, by $\mathbf{A} \mathbf{1}$, the derivative of $\pi_{i}$ w.r.t. any ratio $x_{i} / x_{j}$ is the same, the first-order condition can be written as

$$
v_{x}+v_{G} \frac{\partial G}{\partial x_{i}}-(1+\alpha) p+(n-1) \frac{\partial \pi_{i}}{\partial x_{i j}} \frac{1}{x_{j}} \beta \alpha p\left(x_{i}+(n-1) x_{j}\right)+\pi_{i}\left(\frac{x_{i}}{x_{j}}, \ldots, 1, \ldots, \frac{x_{i}}{x_{j}}\right) \beta \alpha p=0 .
$$

Now we evaluate (80) at the efficient levels $x_{1}=\cdots=x_{n}=x^{*}$ and $G=G^{*}$ as follows. Replace $v_{x}$ in (80) with the efficient level $p$, see (4). Denote the total public goods expenditure by $B=$ $(1-\beta) \alpha p\left(x_{i}+(n-1) x_{j}\right)$ and note that $\frac{\partial B}{\partial x_{i}}=(1-\beta) \alpha p$. We get

$$
C(G)=B \Longleftrightarrow G=C^{-1}(B) \Rightarrow \frac{\partial G}{\partial x_{i}}=\frac{\partial C^{-1}(B)}{\partial B} \frac{\partial B}{\partial x_{i}}=\frac{1}{C^{\prime}(G)}(1-\beta) \alpha p .
$$

Next, replace $v_{G}$ in (80) with the efficient level $\frac{C^{\prime}(G)}{n}$, see (3), and replace $\frac{\partial G}{\partial x_{i}}$ with the term derived in (81). Finally, set $x^{*}=x_{1}=\cdots=x_{n}$. Then (80) becomes

$$
p+\frac{1-\beta}{n} \alpha p-(1+\alpha) p+\left((n-1) \frac{\partial \pi_{i}}{\partial x_{i j}}\right) \frac{1}{x^{*}} \beta \alpha p n x^{*}+\pi_{i}(1, \ldots, 1) \beta \alpha p=0
$$

As mentioned earlier in the text, $\mathbf{A} \mathbf{1}$ implies that in symmetric equilibrium $\frac{\partial \pi_{i}}{\partial x_{i j}}$ is the same for all ratios and players (and denoted by $\left.\pi^{\prime}(1)\right)$ since all ratios $x_{i} / x_{j}$ are equal to one. Moreover, again by $\mathbf{A} \mathbf{1}, \pi_{i}(1, \ldots, 1)=1 / n$. Applying this to (82) and simplifying leads to the left part of (64).

2) Take $C(G)=(1-\beta) P$ and evaluate at $x_{1}=\cdots=x_{n}=x^{*}, G=G^{*}, \alpha=\alpha^{*}$, and $\beta=\beta^{*}$, 
and solve for $\alpha^{*}$.

3) In a symmetric and efficient equilibrium, each player consumes $x^{*}>0$. We only have to ensure that the corresponding $\alpha, \beta$ and $P$ are feasible. In 1) and 2) we derived the values of $\alpha$ and $\beta$ that are consistent with equilibrium existence. Feasibility requires $\alpha^{*}>0$ and $\beta^{*} \in(0,1)$. By A2 and $n \geq 2, \beta^{*}>0$. Moreover, $\beta^{*}<1$ if and only if $\pi^{\prime}(1)>\frac{1}{n^{2}}$. This condition is satisfied for all $n \geq 2$ if it holds for $n=2$. Thus, $\pi^{\prime}(1)>\frac{1}{4}$ ensures feasibility of $\beta^{*}$ for all $n \geq 2$. Given this, $\alpha^{*}>0$ since each factor in the right part of (64) is positive. Finally, $P=\alpha^{*} p n x^{*}>0$.

Proof of proposition 4. Player $i \in \mathcal{N}$ chooses $x_{i}$ in order to maximise

$$
u_{i}=a_{i} \log \left(x_{i}\right)+b_{i} \log \left(\frac{(1-\beta) \sum_{j=1}^{n} \alpha_{j} p x_{j}}{q}\right)-\left(1+\alpha_{i}\right) p x_{i}+\frac{\left(\alpha_{i} p x_{i}\right)^{r}}{\sum_{j=1}^{n}\left(\alpha_{j} p x_{j}\right)^{r}} \beta \sum_{j=1}^{n} \alpha_{j} p x_{j} .
$$

Suppose that tax rates for $j \neq i$ are as in (47) and that players $j \neq i$ consume the efficient amounts $x_{j}^{*}$, from (42). Thus, we replace $\alpha_{j} p x_{j}$ by $A$. Then $i$ 's problem is to maximise

$$
\begin{aligned}
u_{i}= & a_{i} \log \left(x_{i}\right)+b \log \left(\frac{(1-\beta)\left(\alpha_{i} p x_{i}+(n-1) A\right)}{q}\right) \\
& -\left(1+\alpha_{i}\right) p x_{i}+\frac{\left(\alpha_{i} p x_{i}\right)^{r}}{\left(\alpha_{i} p x_{i}\right)^{r}+(n-1) A^{r}} \beta\left(\alpha_{i} p x_{i}+(n-1) A\right) .
\end{aligned}
$$

The first-order condition w.r.t. $x_{i}$ can (straightforwardly) be simplified to

$$
\begin{aligned}
& \frac{a_{i}}{x_{i}}+\frac{b \alpha_{i} p}{\alpha_{i} p x_{i}+(n-1) A}-\left(1+\alpha_{i}\right) p+\frac{r\left(\alpha_{i} p x_{i}\right)^{r-1} \alpha_{i} p(n-1) A^{r}}{\left(\left(\alpha_{i} p x_{i}\right)^{r}+(n-1) A^{r}\right)^{2}} \beta\left(\alpha_{i} p x_{i}+(n-1) A\right) \\
& +\frac{\left(\alpha_{i} p x_{i}\right)^{r}}{\left(\alpha_{i} p x_{i}\right)^{r}+(n-1) A^{r}} \beta \alpha_{i} p=0 .
\end{aligned}
$$

Replacing $x_{i}$ by the efficient quantity (42), replacing $\alpha_{i} a_{i}$ with $A$, and dividing by $\alpha_{i} p$ results in

$$
\frac{b}{n A}-1+\frac{r \beta(n-1)}{n}+\frac{\beta}{n}=0
$$

Inserting $\beta^{*}=1 / r$ and simplifying directly leads to $A=\frac{b r}{r-1}$ as asserted. Budget balance, evaluated at efficient quantities, requires $q G^{*}=(1-\beta)\left(\sum_{j=1}^{n} \alpha_{j} p x_{j}^{*}\right) \Longleftrightarrow b=(1-\beta) A$. With $\beta^{*}=1 / r$ and $A=\frac{b r}{r-1}$, this is satisfied.

\section{Data underlying figure 5}

The following three tables give detailed information on the second-best data presented in figure 5. The numbers underlying the ratio curve is shown in the third from right column of each table. The welfare values were found using numerical methods on a dynamically chosen grid of parameter values. Hence, the presented welfare is a lower bound, we cannot guarantee that there are no other parameter combinations which produce better results. 


\begin{tabular}{|c|c|c|c|c|c|c|c|c|c|c|c|c|}
\hline$a_{1}$ & $a_{2}$ & $a_{1} / a_{2}$ & $\alpha$ & $\beta$ & $r$ & $\alpha_{t}$ & $W^{t}$ & $W^{\text {sb }}$ & $W^{*}$ & ratio & $x_{1}$ & $x_{2}$ \\
\hline 0.05 & 0.95 & 0.0526316 & 0.061 & 0.344 & 0.935 & 0.04 & 3.42191 & 3.42191 & 3.42211 & 0.00216361 & 4.91519777825863 & 93.1629832957107 \\
\hline 0.1 & 0.95 & 0.105263 & 0.056 & 0.32 & 1.027 & 0.0380952 & 3.52171 & 3.52171 & 3.52189 & 0.000363464 & 9.81224013916278 & 93.2630900422982 \\
\hline 0.15 & 0.95 & 0.157895 & 0.082 & 0.557 & 1.109 & 0.0363636 & 3.64766 & 3.64767 & 3.64784 & 0.0202686 & 14.6961900693079 & 93.4018920736804 \\
\hline 0.2 & 0.95 & 0.210526 & 0.338 & 0.897 & 1.096 & 0.0347826 & 3.79061 & 3.79065 & 3.79078 & 0.229922 & 19.4931137687623 & 93.9172157022576 \\
\hline 0.25 & 0.95 & 0.263158 & 0.529 & 0.937 & 1.101 & 0.0333333 & 3.94619 & 3.94628 & 3.94635 & 0.567988 & 24.4605243908690 & 94.5649676935419 \\
\hline 0.3 & 0.95 & 0.315789 & 0.516 & 0.938 & 1.116 & 0.032 & 4.11184 & 4.11196 & 4.11199 & 0.81263 & 29.5847799387865 & 94.9672701853128 \\
\hline 0.35 & 0.95 & 0.368421 & 0.513 & 0.94 & 1.107 & 0.0307692 & 4.28586 & 4.286 & 4.28601 & 0.932611 & 34.7414311779050 & 95.1019141120631 \\
\hline 0.4 & 0.95 & 0.421053 & 0.241 & 0.877 & 1.224 & 0.0296296 & 4.46704 & 4.46718 & 4.46719 & 0.963142 & 39.8021980680446 & 95.0920532389793 \\
\hline 0.45 & 0.95 & 0.473684 & 0.42 & 0.932 & 1.1 & 0.0285714 & 4.65449 & 4.65463 & 4.65463 & 0.990911 & 44.9057890652405 & 95.0730182049204 \\
\hline 0.5 & 0.95 & 0.526316 & 0.14 & 0.803 & 1.337 & 0.0275862 & 4.84751 & 4.84765 & 4.84765 & 0.993336 & 49.9177769418828 & 95.0651792514676 \\
\hline 0.55 & 0.95 & 0.578947 & 0.381 & 0.93 & 1.089 & 0.0266667 & 5.04554 & 5.04567 & 5.04567 & 0.998842 & 54.9652747926136 & 95.0282009658823 \\
\hline 0.6 & 0.95 & 0.631579 & 0.327 & 0.921 & 1.097 & 0.0258064 & 5.24811 & 5.24824 & 5.24824 & 0.999435 & 59.9807935647911 & 95.0193677697512 \\
\hline 0.65 & 0.95 & 0.684211 & 0.25 & 0.9 & 1.121 & 0.025 & 5.45486 & 5.45499 & 5.45499 & 0.99987 & 64.9884852218401 & 95.0104436581376 \\
\hline 0.7 & 0.95 & 0.736842 & 0.245 & 0.901 & 1.116 & 0.0242424 & 5.66546 & 5.66558 & 5.66558 & 0.999922 & 69.9931143373408 & 95.0040568902275 \\
\hline 0.75 & 0.95 & 0.789474 & 0.245 & 0.904 & 1.11 & 0.0235294 & 5.87964 & 5.87975 & 5.87975 & 0.999962 & 74.9998915481710 & 95.0057697188150 \\
\hline 0.8 & 0.95 & 0.842105 & 0.243 & 0.906 & 1.106 & 0.0228571 & 6.09714 & 6.09726 & 6.09726 & 0.99991 & 80.0034303136872 & 95.0062460753276 \\
\hline 0.85 & 0.95 & 0.894737 & 0.247 & 0.91 & 1.1 & 0.0222222 & 6.31778 & 6.31789 & 6.31789 & 0.99996 & 85.0030620625687 & 95.0039866961854 \\
\hline 0.9 & 0.95 & 0.947368 & 0.243 & 0.911 & 1.098 & 0.0216216 & 6.54136 & 6.54146 & 6.54146 & 0.999986 & 90.0011129403903 & 95.0012372714665 \\
\hline 0.95 & 0.95 & 1. & 0.2395 & 0.9121 & 1.0964 & 0.0210526 & 6.76771 & 6.76782 & 6.76782 & 1. & 95.0003249931925 & 95.0003249931925 \\
\hline
\end{tabular}

Table of values underlying the $k=1$ welfare ratio curve in figure 5 .

\begin{tabular}{|c|c|c|c|c|c|c|c|c|c|c|c|c|}
\hline$a_{1}$ & $a_{2}$ & $/ a_{2}$ & $\alpha$ & $\beta$ & $r$ & $\alpha_{t}$ & $W^{t}$ & $W^{\mathrm{sb}}$ & $W^{*}$ & ratio & $x_{1}$ & $x_{2}$ \\
\hline 0.05 & 95 & 316 & 05 & & & 0.04 & 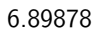 & & 57 & 32 & 13 & 5 \\
\hline & 95 & & 48 & & & & & & & & & \\
\hline 0.15 & 95 & 5 & 45 & 88 & & 36 & 35033 & 35095 & 35114 & 770952 & 0915 & 913 \\
\hline 0.2 & 95 & 26 & 041 & 7 & 47 & 26 & 525 & 7.63681 & 701 & 721 & 325 & 207 \\
\hline 0.25 & 15 & & & & & & & & & & & \\
\hline 0.3 & .95 & 39 & 08 & 37 & 4 & 0.0 & & 8.27929 & & & & \\
\hline 0.35 & 95 & 21 & 459 & 33 & & & 578 & 8.62736 & & & & \\
\hline 0.4 & 95 & & & & & & & & & & & \\
\hline 0.45 & 95 & 34 & 0.397 & 0 & 1.078 & & & 9.3 & & & & 95. \\
\hline 0.5 & 0.95 & & 0.328 & 916 & 1. & & 013 & 9.75071 & & & & \\
\hline 0.55 & .95 & 7 & 296 & 0.91 & 1.1 & 67 & 62 & 168 & 68 & 82 & 458 & \\
\hline 0.6 & 0.95 & & 0.323 & & 1.087 & & & & & & & \\
\hline 0.65 & 95 & 4211 & 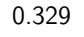 & 21 & 1.083 & & 649 & 10.9654 & 654 & 659 & 863 & 95. \\
\hline 0.7 & 0.95 & 2 & 0.332 & 0.927 & 1.079 & 24 & 61 & 66 & 66 & 13 & 08 & 92 \\
\hline 0.75 & 0.95 & 0.789474 & 0.327 & 0.928 & 1.078 & 0.0235294 & 11.8144 & 11.8149 & 11.815 & 0.992348 & 76325 & 95.11 \\
\hline 0.8 & 0.95 & 05 & 0.327 & & 1.075 & 571 & 12.2495 & 12.25 & 12.25 & 586 & 16822845 & 95.07 \\
\hline 0.85 & 0.95 & 0.894737 & 0.327 & 0.932 & 1.073 & & 12.6907 & 12.6912 & 12.6912 & & & \\
\hline 0.9 & 0.95 & 0.947368 & 0.328 & 0.934 & 1.071 & 0.0216216 & 13.1379 & 13.1384 & 13.1384 & 0.999459 & 89.9760526690674 & 95.03528 \\
\hline 0.95 & 95 & 1. & 0.33 & 2 & 681 & .0210526 & 906 & & & & 94.998 & $94.99892 C$ \\
\hline
\end{tabular}

Table of values underlying the $k=2$ welfare ratio curve in figure 5 . 


\begin{tabular}{|c|c|c|c|c|c|c|c|c|c|c|c|c|}
\hline$a_{1}$ & $a_{2}$ & $a_{1} / a_{2}$ & $\alpha$ & $\beta$ & $r$ & $\alpha_{t}$ & $W^{t}$ & $W^{\mathrm{sb}}$ & $W^{*}$ & ratio & $x_{1}$ & $x_{2}$ \\
\hline 0.05 & 0.95 & 0.0526316 & 0.047 & 0.147 & 7.851 & 0.04 & 10.3965 & 10.398 & 10.3982 & 0.929371 & 4.80621243895634 & 94.9975312262083 \\
\hline 0.1 & 0.95 & 0.105263 & 0.044 & 0.131 & 8.43 & 0.0380952 & 10.696 & 10.6973 & 10.6975 & 0.870484 & 9.63735937931340 & 94.9974044287105 \\
\hline 0.15 & 0.95 & 0.157895 & 0.04 & 0.087 & 12.24 & 0.0363636 & 11.0739 & 11.0751 & 11.0754 & 0.834025 & 14.5080036104712 & 94.9982381879671 \\
\hline 0.2 & 0.95 & 0.210526 & 0.039 & 0.103 & 9.863 & 0.0347826 & 11.5028 & 11.5039 & 11.5042 & 0.778594 & 19.3578958950025 & 94.9966046119057 \\
\hline 0.25 & 0.95 & 0.263158 & 0.641 & 0.948 & 1.047 & 0.0333333 & 11.9695 & 11.9705 & 11.9709 & 0.746704 & 24.2519706302841 & 94.9144493611719 \\
\hline 0.3 & 0.95 & 0.315789 & 0.64 & 0.95 & 1.046 & 0.032 & 12.4665 & 12.4675 & 12.4678 & 0.795243 & 29.2749173276169 & 95.0046255462645 \\
\hline 0.35 & 0.95 & 0.368421 & 0.615 & 0.95 & 1.048 & 0.0307692 & 12.9886 & 12.9896 & 12.9899 & 0.837255 & 34.3185043988500 & 95.1322543728825 \\
\hline 0.4 & 0.95 & 0.421053 & 0.644 & 0.954 & 1.045 & 0.0296296 & 13.5322 & 13.5332 & 13.5334 & 0.873697 & 39.3763240652440 & 95.1921233015644 \\
\hline 0.45 & 0.95 & 0.473684 & 0.649 & 0.956 & 1.044 & 0.0285714 & 14.0946 & 14.0956 & 14.0957 & 0.903424 & 44.4441040506193 & 95.2416436105510 \\
\hline 0.5 & 0.95 & 0.526316 & 0.657 & 0.958 & 1.042 & 0.0275862 & 14.6736 & 14.6747 & 14.6748 & 0.927667 & 49.5052040726984 & 95.2260173030242 \\
\hline 0.55 & 0.95 & 0.578947 & 0.65 & 0.959 & 1.042 & 0.0266667 & 15.2677 & 15.2688 & 15.2688 & 0.946934 & 54.5836831851615 & 95.2592965622003 \\
\hline 0.6 & 0.95 & 0.631579 & 0.645 & 0.96 & 1.041 & 0.0258064 & 15.8755 & 15.8765 & 15.8766 & 0.962296 & 59.6449413762128 & 95.2304993549295 \\
\hline 0.65 & 0.95 & 0.684211 & 0.641 & 0.961 & 1.04 & 0.025 & 16.4958 & 16.4968 & 16.4968 & 0.974196 & 64.7037190686612 & 95.1989281266717 \\
\hline 0.7 & 0.95 & 0.736842 & 0.638 & 0.962 & 1.039 & 0.0242424 & 17.1276 & 17.1286 & 17.1286 & 0.983246 & 69.7596270200692 & 95.1655947940557 \\
\hline 0.75 & 0.95 & 0.789474 & 0.636 & 0.963 & 1.038 & 0.0235294 & 17.7701 & 17.7711 & 17.7711 & 0.989935 & 74.8124841979519 & 95.1312698958483 \\
\hline 0.8 & 0.95 & 0.842105 & 0.635 & 0.964 & 1.037 & 0.0228571 & 18.4227 & 18.4236 & 18.4236 & 0.994662 & 79.8622508505479 & 95.0965388639049 \\
\hline 0.85 & 0.95 & 0.894737 & 0.635 & 0.965 & 1.036 & 0.0222222 & 19.0846 & 19.0855 & 19.0855 & 0.997746 & 84.9089816189104 & 95.0618456676533 \\
\hline 0.9 & 0.95 & 0.947368 & 0.636 & 0.966 & 1.035 & 0.0216216 & 19.7553 & 19.7562 & 19.7562 & 0.99945 & 89.9527926175376 & 95.0275268716559 \\
\hline 0.95 & 0.95 & 1. & 0.638 & 0.967 & 1.0341 & 0.0210526 & 20.4344 & 20.4353 & 20.4353 & 0.999999 & 94.9987050339547 & 94.9987050339547 \\
\hline
\end{tabular}

Table of values underlying the $k=3$ welfare ratio curve in figure 5 .

\section{References}

Bergstrom, T., L. Blume, and H. Varian (1986): "On the Private Provision of Public Goods," Journal of Public Economics, 29, 25-40.

Bergstrom, T., and R. Cornes (1983): "Independence of Allocative Efficiency from Distribution in the Theory of Public Goods," Econometrica, 51, 1753-66.

Bierbrauer, F. (2009): "A note on optimal income taxation, public goods provision and robust mechanism design," Journal of Public Economics, 93(5-6), 667-70.

Bierbrauer, F., And M. Hellwig (2009): "Public-Good Provision in a Large Economy," Max Planck Institute for Research on Collective Goods, Working Paper \#2010/02.

Bos, O. (2011): “How Lotteries Outperform Auctions," Economic Letters, 110, 262-4.

Brett, C., And J. A. Weymark (2008): "Public Good Provision And The Comparative Statics Of Optimal Nonlinear Income Taxation," International Economic Review, 49(1), 255-90.

Buchholz, W., R. Cornes, And D. RübBelke (2011): "Interior matching equilibria in a public good economy: An aggregative game approach," Journal of Public Economics, 95, 63945.

Carpenter, J., J. Holmes, And P. H. Matthews (2008): "Charity auctions: A field experiment," Economic Journal, 118, 92-113.

Clotfelter, C. T., And P. J. Cook (1989): Selling Hope: State Lotteries in America. Harvard University Press, Cambridge, Mass.

Corazzini, L., M. Faravelli, and L. Stanca (2010): "A Prize To Give For: An Experiment on Public Good Funding Mechanisms," Economic Journal, 120, 944-67. 
Deaton, A. (1981): "Optimal Taxes and the Structure of Preferences," Econometrica, 49, 124560.

Dixit, A. (1987): "Strategic Behavior in Contests," American Economic Review, 77, 891-98.

Duffy, J., And A. Matros (2012): "All-Pay Auctions vs. Lotteries as Provisional Fixed-Prize Fundraising Mechanisms: Theory and Evidence," University of Pittsburgh, Working Paper.

Franke, J., And W. Leininger (2013): "On the Efficient Provision of Public Goods by Means of Lotteries," Technische Universität Dortmund; Ruhr Economic Papers, \#399.

FU, Q., AND J. LU (2012): "Micro foundations of multi-prize lottery contests: a perspective of noisy performance ranking," Social Choice and Welfare, 38, 497-517.

Gershkov, A., J. Li, And P. Schweinzer (2009): "Efficient Tournaments within Teams," Rand Journal of Economics, 40(1), 103-19.

Goeree, J. K., E. Maasland, S. Onderstal, and J. L. Turner (2005): "How (Not) to Raise Money," Journal of Political Economy, 113, 897-926.

Green, J. R., And N. Stokey (1983): “A Comparison of Tournaments and Contracts," Journal of Political Economy, 91, 349-64.

Hansen, A. (2005): "State-Run Lotteries as a Form of Taxation," State Tax Notes, 38(10).

Hirshleifer, J. (1989): "Conflict and rent-seeking success functions: Ratio vs. difference models of relative success," Public Choice, 63, 101-12.

JiA, H. (2008): "A stochastic derivation of the ratio form of contest success functions," Public Choice, 135, 125-30.

Karoshi, B. (2008): How to Win the Lottery ... by not playing. Bryan S Mangam, Lulu.com.

Kolmar, M., And D. SisaK (2011): "(In)Efficient Public-Goods Provision Through Contests," University of St. Gallen, Working Paper, June 13, 2011.

Kolmar, M., and A. Wagener (2011): "Contests and the Private Provision of Public Goods," Southern Economic Journal, forthcoming.

Konrad, K. (2008): Strategy and Dynamics in Contests. Oxford University Press, Oxford.

LAndry, C. E., And M. K. Price (2007): "Earmarking lottery proceeds for public goods: Empirical evidence from U.S. lotto expenditures," Economic Letters, 95, 451-55.

Lange, A., J. A. List, And M. K. Price (2007): "Using Lotteries to Finance Public Goods: Theory and Experimental Evidence," International Economic Review, 48, 901-27.

Lazear, E., And S. Rosen (1981): "Rank Order Tournaments as Optimal Labor Contracts," Journal of Political Economy, 89, 841-64.

Ledyard, J. O., And T. R. Palfrey (1994): "Voting and Lottery Drafts as Efficient Public Goods Mechanisms," Review of Economic Studies, 61, 327-55.

Mankiw, N. G., M. Weinzierl, and D. Yagan (2009): "Optimal Taxation in Theory and Practice," Journal of Economic Perspectives, 23, 147-74. 
Moir, R., And J. Childs (2005): "Lotteries as a funding tool for financing public goods," University of New Brunswick in Saint John, Working Paper \#0401.

Moldovanu, B., And A. Sela (2001): "The Optimal Allocation of Prizes in Contests," American Economic Review, 91(3), 542-58.

Morgan, P. (2000): "Financing Public Goods by Means of Lotteries," Review of Economic Studies, 67, 761-84.

Morgan, P., And M. Sefton (2000): "Financing Public Goods with Lotteries: Experimental Evidence," Review of Economic Studies, 67, 785-810.

Nalebuff, B. J., And J. E. Stiglitz (1983): "Prizes and Incentives: Towards a General Theory of Compensation and Competition," Bell Journal of Economics, 14, 21-43.

Orzen, H. (2005): "Fundraising through competition: Evidence from the lab," CeDEx Working Paper, \#200504.

Polanski, A., And E. Winter (2010): "Two-Sided Markets with Repeated Transactions," BE Press Journal of Theoretical Economics, 10.

Roussillon, B., And P. Schweinzer (2010): "Efficient Emissions Reduction," University of Manchester discussion paper, EDP-1004.

Samuelson, P. A. (1954): "The Theory of Public Expenditure," Review of Economics and Statistics, 36, 386-89.

Schönbein, S. (2008): Das Millionenspiel mit Tradition: Die Geschichte der Klassenlotterie. Books on Demand, ISBN 978-3-8334-8779-8.

Schram, A. J., And S. Onderstal (2009): "Bidding to Give: An Experimental Comparison of Auctions for Charity," International Economic Review, 50, 431-57.

Schweinzer, P., And E. Segev (2012): "The optimal prize structure of symmetric Tullock contests," Public Choice, 153, 69-82.

Siegel, R. (2009): "All-pay Contests," Econometrica, 77, 71-92.

Silvestre, J. (2003): "Wicksell, Lindahl and the Theory of Public Goods," Scandinavian Journal of Economics, 103, 527-53.

Skaperdas, S. (1996): "Contest Success Functions," Economic Theory, 7(2), 283-90.

WAN, J. (2010): "The Incentive to Declare Taxes and Tax Revenue: The Lottery Receipt Experiment in China," Review of Development Economics, 14, 611-24. 